\title{
Chapter7
}

\section{Ageing and durability of organic polymers}

\author{
Jacques Verdu; Bruno Fayolle
}

\section{Definitions. General comments}

\subsubsection{Ageing}

"Ageing" is any slow and irreversible phenomenon (under usage conditions) of a material's structure, morphology or composition, under the effects of its own instability and/or interaction with the environment.

Any condition is considered to be slow when the kinetics are not apprehensible in a time scale which is compatible with economic restraints.

The classic approach of predicting long-term behavior consists of carrying out accelerated tests simulating, as accurately as possible, natural ageing and to presume that the hierarchy of stability for several materials is the same in accelerated and natural ageing. The modern approach consists of developing a kinetic model derived from analyzing degradation materials. Accelerated ageing is, then, used to identify the model parameters.

\subsubsection{Lifetime}

The lifetime $\left(t_{F}\right)$ is specific to a property $(\mathrm{P})$ of the material, as crucial as possible for the application considered, and for which it is possible to define a critical value $\mathrm{P}_{\mathrm{f}}$. Beyond this value, the material will no longer be capable of fulfilling its function. The 
kinetic model must allow the following function to be established: $\quad P=f(t)$, which describes the evolution of $\mathrm{P}$ over the ageing process. The lifetime is then defined by:

$$
t_{F}=f^{-1}\left(P_{F}\right)
$$

where $\mathrm{f}^{-1}$ is the reciprocal function of $\mathrm{f} . \mathrm{P}_{\mathrm{F}}$ is often called the end-of-life criterion.

\subsubsection{Extrapolation principle}

The classic approach consists of considering that the simple laws established for basic processes also apply to complex processes, such as ageing. For example, in thermal ageing (a rise in temperature leading to acceleration), we can write:

$$
\mathrm{t}_{\mathrm{F}}=\mathrm{t}_{\mathrm{F} 0} \exp \left(\frac{\mathrm{E}}{\mathrm{RT}}\right) \quad \text { (Arrhenius law) }
$$

The tests accelerated at different temperatures enable us to identify $\mathrm{t}_{\mathrm{F} 0}$ and $\mathrm{E}$. Next, it is then sufficient to extrapolate to use temperature to obtain lifetime.

In the case of ageing by irradiation (photo or radiochemical), it may be useful to consider that the end-of-life is an isodose state, in other words:

$$
\dot{\mathrm{d}}_{\mathrm{a}} \mathrm{t}_{\mathrm{Fa}}=\dot{\mathrm{d}}_{\mathrm{u}} \mathrm{t}_{\mathrm{Fu}}
$$

where $\mathrm{d}$ is the dose rate (light intensity for photochemical ageing), indices a and $\mathrm{u}$ are specific to accelerated and natural ageing, respectively.

In fact, neither of the two laws above can be considered as being systematically valid for ageing. Using these laws without control may lead to important errors of appreciation.

For kinetic approaches, the ageing mechanism is divided into elementary processes. For each of these processes, the laws mentioned above are applicable, when reformulated in terms of elementary rates:

$$
\mathrm{v}_{\mathrm{i}}=\mathrm{v}_{\mathrm{i} 0} \exp \left(-\frac{\mathrm{E}_{\mathrm{i}}}{\mathrm{RT}}\right) \text { et } \mathrm{v}_{\mathrm{j}}=\mathrm{G} \dot{\mathrm{d}}
$$


The global kinetic function $\mathrm{P}=\mathrm{f}(\mathrm{t})$ includes all the associated elementary kinetic parameters in a more or less complex mathematical equation. Extrapolation under natural ageing conditions will be achieved by extrapolating all the elementary parameters by their associated law.

Let us use a simple example from thermal ageing where the total rate is the sum of the rates of two elementary processes which obey the Arrhenius law:

$$
\mathrm{v}=\mathrm{v}_{0 \mathrm{a}} \exp \left(-\frac{\mathrm{H}_{\mathrm{a}}}{\mathrm{RT}}\right)+\mathrm{v}_{0 \mathrm{~b}} \exp \left(-\frac{\mathrm{H}_{\mathrm{b}}}{\mathrm{RT}}\right)
$$

The elementary process rates are equal at temperature $\mathrm{T}_{\mathrm{C}}$, such as:

$$
\mathrm{T}_{\mathrm{c}}=\frac{\mathrm{H}_{\mathrm{b}}-\mathrm{H}_{\mathrm{a}}}{\operatorname{R} \cdot \operatorname{Ln}\left(\frac{\mathrm{v}_{0 \mathrm{~b}}}{\mathrm{v}_{0 \mathrm{a}}}\right)}
$$

Away from $T_{c}$, one of the processes is insignificant in relation to the other, and the Arrhenius law may be an acceptable estimation to calculate $\mathrm{v}$ :

$$
\mathrm{v} \approx \mathrm{v}_{0 \mathrm{i}} \exp \left(-\frac{\mathrm{H}_{\mathrm{i}}}{\mathrm{RT}}\right)
$$

with $\mathrm{i}=\mathrm{a}$ or $\mathrm{b}$.

On the other hand, around temperature $\mathrm{T}_{\mathrm{c}}$, $\mathrm{v}$ does not obey the Arrhenius law at all. In this domain, lifetime predictions bypass the identification of the parameters which characterize the elementary processes $\mathrm{v}_{0 a}, \mathrm{H}_{\mathrm{a}}, \mathrm{v}_{0 \mathrm{~b}}, \mathrm{H}_{\mathrm{b}}$ and the calculation of the sum of the two Arrhenius terms.

In practice, cases when the total rate of a process results from the sum of elementary rates are not rare. 


\subsubsection{Induction period}

In many cases, ageing kinetics are characterized by the existence of an initial period during which there is no noticeable evolution of the polymer usage properties (Figure 7.1).

Generally, an induction period is a period of time over which the material preserves its original properties. There are three main reasons which explain such behavior (largely non-linear behavior, it must be said):

- induction phenomenon is specific to the chemical reaction responsible for ageing. Oxidation processes (radical reactions in branched chains) often manifest this characteristic at low temperatures (typically when $\mathrm{T} \leq 150^{\circ} \mathrm{C}$ );

- induction phenomenon is related to the presence of an efficient stabilizer. So long as this stabilizer is not completely consumed, degradation remains insignificant;

- the chemical structure evolves under an ageing effect, but the considered properties only evolve beyond one threshold. Embrittlement phenomena often manifest this characteristic.

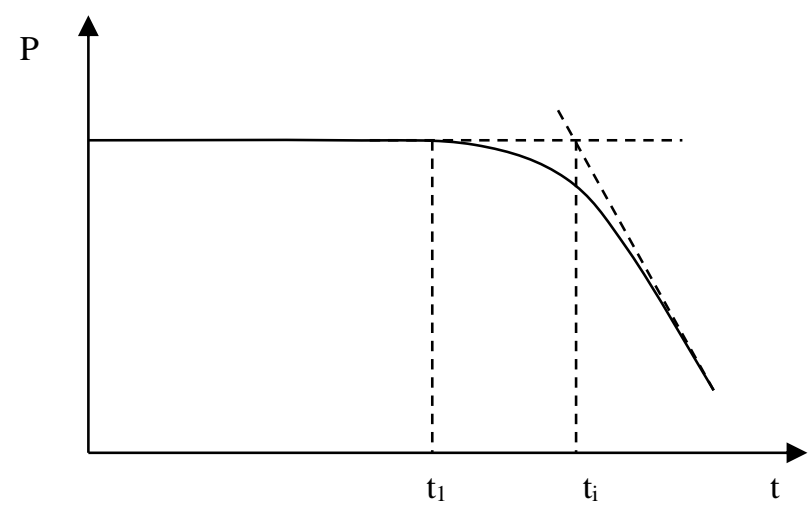

Figure 7.1. Diagram representing kinetics of the evolution of usage property $P$ with an induction period of length $t_{i}$

Obviously the combination of two or three causes above is not excluded.

Figure 7.1 enables us to understand the remote amount of interest, so as not to say the uselessness, in punctual tests based on the study of one ageing duration length. For example, a duration test where $t_{1}<t_{i}$ lets us establish that $t_{i}$ is higher than the test time, but we cannot be sure, however, if $t_{1}=0.95 t_{i}$ or $0.1 t_{i}$ or $0.01 t_{i}$. 
In conclusion, any analysis relevant to ageing bypasses the stage where the kinetic curves of the material's evolution are established in unique time scales which allow for a significant evolution, if possible to a state where it would then be considered unsuitable for the characterized usage.

\subsubsection{Different types of ageing}

\subsubsection{Chemical ageing}

Ageing induced by a chemical modification of the material's structure.

\subsubsection{Physical ageing}

Ageing affecting chain conformation, morphology or the material composition without changing the chemical structure of the macromolecules.

\subsubsection{Thermal ageing}

Ageing where the kinetics only depend on temperature and atmospheric composition. This can be either physical, chemical or both.

\subsubsection{Wet ageing}

Ageing induced by the interaction of the material with water present in the environment, either as a liquid or vapor. This interaction can be either physical or chemical.

\subsubsection{Photochemical ageing}

Chemical ageing induced by the interaction of a polymer with light rays (generally solar UV radiation), where oxygen from the atmosphere generally plays a large role (photo-oxidation).

\subsubsection{Radiochemical ageing}

Chemical ageing induced by the interaction of a polymer with ionizing rays $(\gamma, \beta, \alpha$, neutrons, etc.), where oxygen from the atmosphere may play a large role, especially at low dose rates.

\subsubsection{Biochemical ageing}

Chemical ageing induced by the interaction of a polymer with living organisms (bacteria, moulds, etc.). 


\subsection{Physical ageing}

\subsubsection{Physical ageing by structural relaxation (broad meaning)}

The two phenomena responsible for the solidification of polymers at the end of their processing operations are vitrification and crystallization. Both of which are kinetic phenomena which lead to a thermodynamic state out of equilibrium. Glasses have an excess of unstable conformations and free volume (section 5.2.5). Semicrystalline polymers are not completely crystallized; their melting point is clearly lower (often by a few tens of degrees) than its equilibrium value.

If, in their use conditions, a residual molecular mobility takes place in these polymers ( $\beta$ movements in glass, $\alpha$ movements in the rubbery amorphous phase of semi-crystallines), then they will slowly move towards an equilibrium (structural relaxation).

The general characteristics of this type of ageing (wrongly called "physical" ageing because there are other physical mechanisms of ageing) are the following:

- ageing results in a compacification of the matrices and a loss of enthalpy;

- the stress at the plastic yield increases;

- the creep compliance decreases;

- evolution slows down but may continue over recorded time.

The evolution of creep compliance $\mathrm{J}(\mathrm{t})$ has been the subject of quantitative studies, particularly by Struik [STU 78] for organic glass.

The creep curves of samples aged during $t_{v}, 10 t_{v}, 100 t_{v}$, etc., take the shape seen in Figure 7.2.

If we say that $a_{v}=\log \left(\frac{t_{1 v}}{t_{2 v}}\right)$ is the logarithm of the ageing time ratio, and $a_{\mathrm{fl}}=\log \left(\frac{\mathrm{t}_{1 \mathrm{fl}}}{\mathrm{t}_{2 \mathrm{fl}}}\right)$ the corresponding interval of the creep curves on the logarithmic time scale, we observe that $\frac{\mathrm{a}_{\mathrm{v}}}{\mathrm{a}_{\mathrm{fl}}} \approx 1$. 
In other words, increasing the ageing time by a decade causes an increase in the characteristic creep time by approximately a decade.

This is a very general property of structural relaxation ageing, whether it is a question of polymers, molecular organic materials (glucose), sand heaps or emulsions.

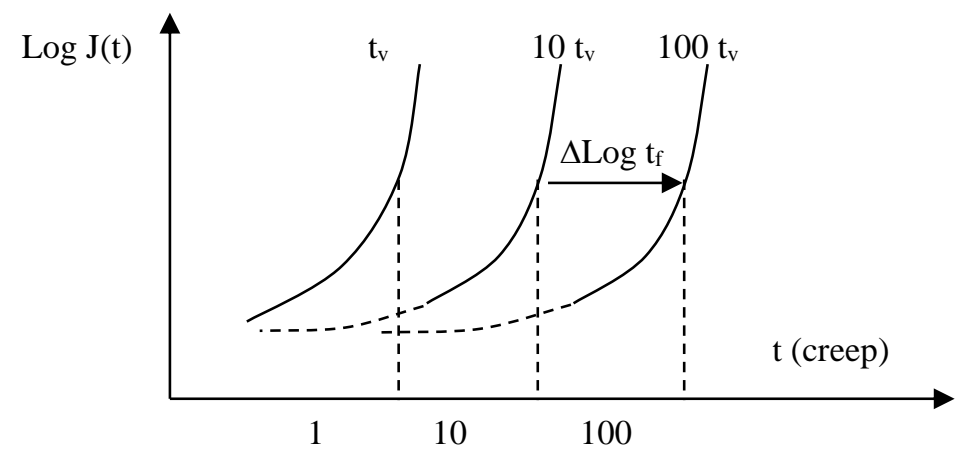

Figure 7.2. Creep curve (in a log - log scale), of aged samples $T_{V}, 10 t_{v}$ and $100 t_{v}$ at a temperature lower than $T_{g}$

The reduction in creep compliance, as with the stress increase at the plastic yield, would be an advantage in many applications. Unfortunately, it is compensated by an important reduction in ductility/toughness (Figure 7.3a).

Increasing yield stress (up to $20 \mathrm{MPa}$ for a polymer such as polycarbonate), the loss of ductility without altering the molar mass distribution, and the appearance of an endotherm in the immediate vicinity of $\mathrm{T}_{\mathrm{g}}$ (Figure $7.3 \mathrm{~b}$ ) allows us to recognize structural relaxation ageing from another type of ageing, in the case of an amorphous glassy polymer. 


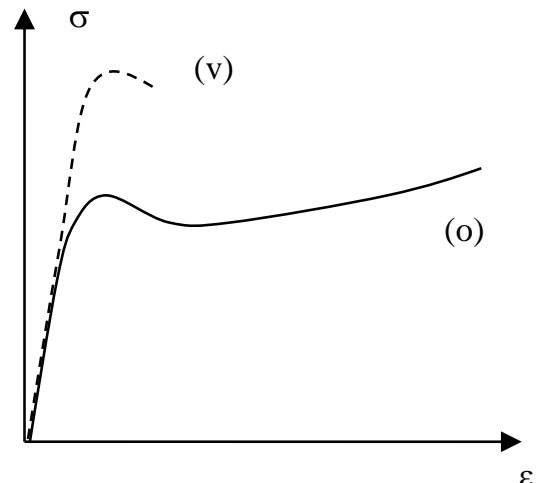

(a)
$\mathrm{C}_{\mathrm{p}}$

(

(o)

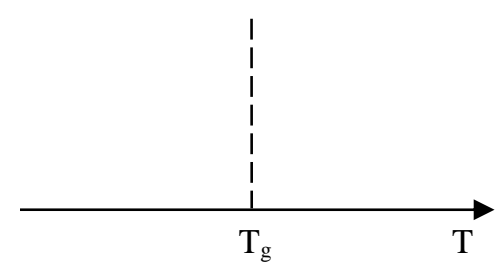

(b)

Figure 7.3. a) Shape of stress-strain curves from a new sample (o) and from a sample subjected to ageing under structural relaxation (v). b) shape of (DSC) thermograms from a new sample $(o)$ and from a sample subjected to ageing under structural relaxation $(v)$

\subsubsection{Ageing by solvent absorption}

Solvents plasticize polymers and therefore lead to a reduction in $\mathrm{T}_{\mathrm{g}}$ and a reduction in the yield stress in a ductile system.

However the most important effects, in practice, appear when the polymer is subjected to static stress.

Indeed, plasticization favors damage, in particular by crazing.

For example, let us consider a creep test where damage is detected by an optical method.

The behavior is represented by Figure 7.4. 


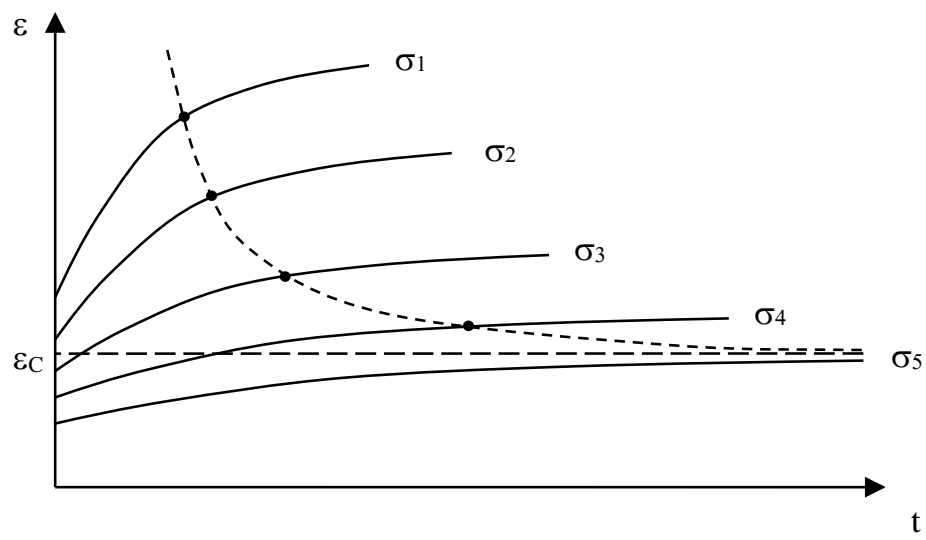

Figure 7.4. Shape of the creep curves in the presence of a solvent. $\sigma_{1}>\sigma_{2}>\sigma_{3} \ldots$ etc. The black points represent onset of damage. The envelope of the points has a horizontal asymptote

$$
\text { at } \varepsilon=\varepsilon_{C}
$$

We can see that there is a critical strain $\varepsilon_{C}$, below which the material will not be damaged. Value $\varepsilon_{C}$ is according to the polymer/solvent pair.

In simple cases (only slightly polar polymers, such as Polyphenyleneoxide (PPO), $\varepsilon_{\mathrm{C}}$ varies with the solvent's solubility parameter, according to Figure 7.5.

We must remember that certain vapors $\left(\mathrm{H}_{2} \mathrm{O}, \mathrm{CO}_{2}\right)$ are very important. In addition, the plasticizers themselves can migrate from one polymer into the other and induce damage under stress.

Where complex parts are concerned, localized damage in the presence of solvent vapors may reveal the presence of residual stresses.

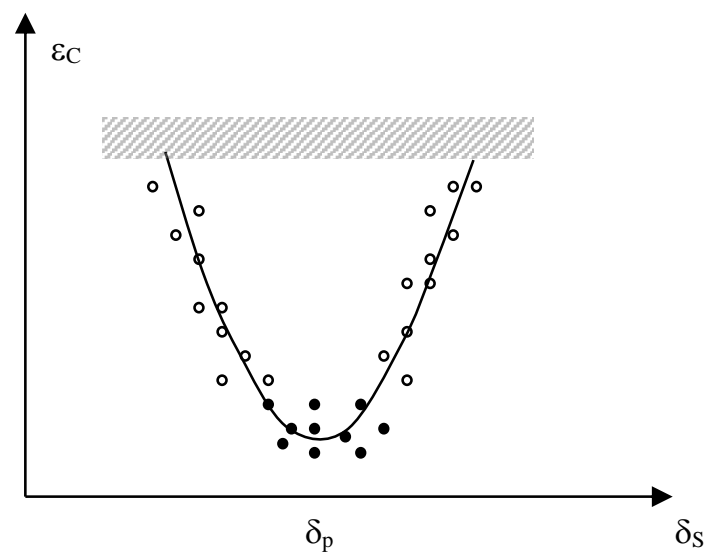


Figure 7.5. Shape of the critical strain variation $\varepsilon_{C}$ with the solvent's solubility parameter in the case of PPO. The curve's minimum corresponds to $\delta s_{s}=\delta$ (the polymer's solubility parameter). (०): crazes. (•): open cracks. The hatched area relates to the $\varepsilon_{C}$ values observed in the air. NB For polar polymers (PMMA for instance), the behavior is more complex, the curve $\varepsilon C=f(\delta s)$ may include several minima.

Solvent penetration in a polymer results in swelling, which can also generate strains related to differential. Damage problems induced by water diffusion in organic matrix composites have been, and are still, the subject of active research, particularly in aeronautics.

\subsubsection{Ageing by additive migration}

Thermodynamically, a polymer + additive mix is out of equilibrium. Since the additive's concentration in the surrounding environment is nul, there is no equality in its chemical potential within the environment and the polymer.

To restore this equality and move towards equilibrium, the additive tends to migrate out of the polymer. This migration is made up of two stages (Figure 7.6).

The first stage is the movement into the environment for the molecules close to the surface, in other words, crossing over into the polymer/environment interface. In gaseous environments, (e.g., the atmosphere), the evaporation of the additive is responsible for this stage. In liquid environments, the additive's dissolution by the said liquid plays the same role. Let us note that a second polymer, in contact with the first, may play the same role as a liquid. Polymers also have a tendency to switch stabilizers. Plasticizers (PVC, for example) are well-known for their tendency to migrate into all sorts of polymers.

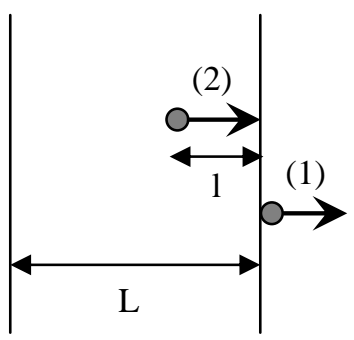


Figure 7.6. Diagram representing the two stages of a polymer's migration outside a polymer

The second stage begins as soon the first molecules of the additive which leave during the first stage have created a concentration gradient. This is the "motor" of the molecular diffusion occurring in the core towards the surface. Duration $t_{d}$ of the molecule's path of length 1 is given, in the case of diffusion which obeys the Fick law by:

$$
\mathrm{t}_{\mathrm{d}}=\frac{1^{2}}{\mathrm{D}}
$$

We can see that $t_{d}$ rapidly increases with the sample's thickness $L$.

Therefore, we can now distinguish two kinetic regimes.

\subsubsection{Mode controlled by evaporation (or dissolution)}

When $\mathrm{L}$ is low (fibers, films) and diffusivity D is high enough, evaporation is slower than diffusion and therefore controls the migration's total kinetics.

Thus, concentration $\mathrm{C}$ of the additive in the polymer decreases in an exponential way with time:

$$
\frac{\mathrm{dC}}{\mathrm{dt}}=-\mathrm{HC}
$$

The evaporation rate constant $\mathrm{H}$ decreases with the additive molar mass and its cohesive energy density.

\subsubsection{Mode controlled by additive diffusion}

When $\mathrm{L}$ is high and $\mathrm{D}$ is low, diffusion controls kinetics. In the simplest of cases, the Fick law is applied:

$$
\frac{\partial \mathrm{m}}{\partial \mathrm{t}}=\mathrm{D} \frac{\partial^{2} \mathrm{~m}}{\partial \mathrm{x}^{2}}(\mathrm{~m}=\text { mass variation related to additive loss })
$$

In the initial time period, the mass decreases in proportion to the square root of the time. A concentration gradient is established in the thickness of the sample (Figure 7.7). 

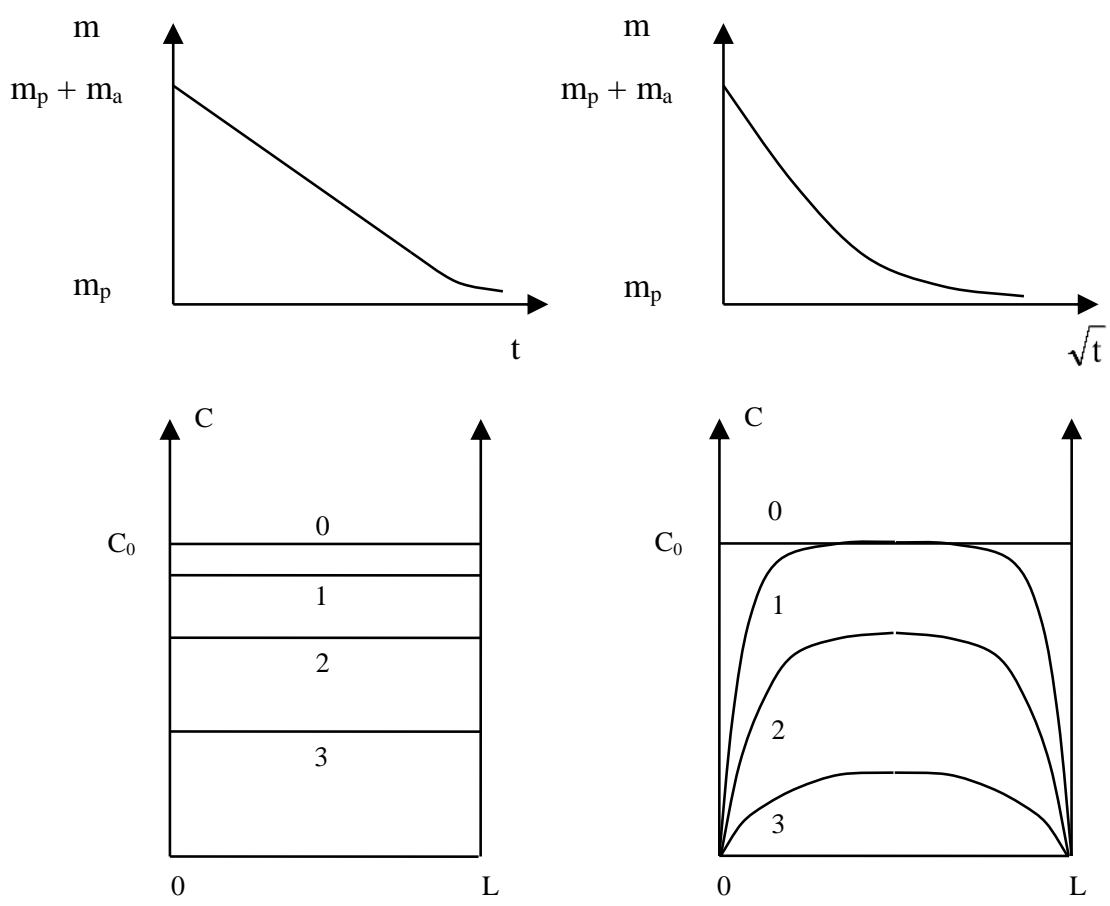

Figure 7.7. Migration controlled by evaporation (left) and by diffusion (right). Top: shape of the kinetic curves of mass evolution. $m_{p}+m_{a}=$ polymer mass + additive mass $\left(m_{p}=\right.$ polymer mass). Bottom: additive concentration profile in the sample's thickness at different times: $0<$ $t_{1}<t_{2}<t_{3}<t_{4}$

When the additives have relatively high molar masses, their evaporation (or generally, their cross over from the polymer/environment interface) is slow. Their concentration at the surface is thus intermediate between the initial concentration $\mathrm{C}_{0}$ and 0 . This boundary condition must be taken into account to solve the diffusion equation.

When the additives are strongly concentrated (e.g. plasticizers) they change matrix properties, and their diffusivity then becomes a function of their concentration (D increases with C). There are some complications which may arise when the additive's migration is accompanied by a phase transition, for example, in the case of plasticized PVC we may expect the profile seen in Figure 7.8. 


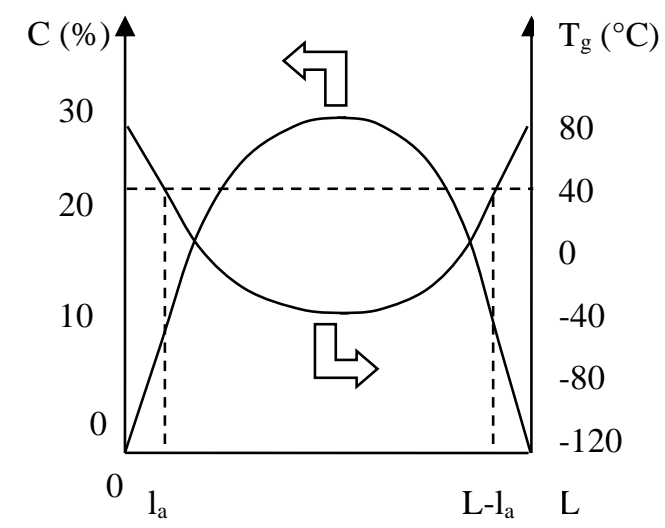

Figure 7.8. Presumed shape of the concentration profile in the plasticizer (mass fraction) and the local glass transition temperature in a plasticized PVC sample subjected to ageing at

room temperature

We can see, however, that in the central area, the polymer has retained a rubbery state. On the other hand, in a superficial layer of thickness $l_{\mathrm{a}}$, the polymer is glassy. As the diffusion coefficient varies from at least one order of magnitude at glass transition, the real profile will be more likely to take the shape seen in Figure 7.9.

In such cases, the diffusion front is very abrupt and the mass variation is a linear time function.

In terms of usage properties, a loss of additives may result in the loss of properties that they were supposed to bring originally: long term resistance for stabilizers, flexibility for plasticizers, etc. When the additives are initially strongly concentrated (plasticizers), their loss leads to volume shrinkage (mass loss). The volume shrinkage may generate strains and lead to crack growth.

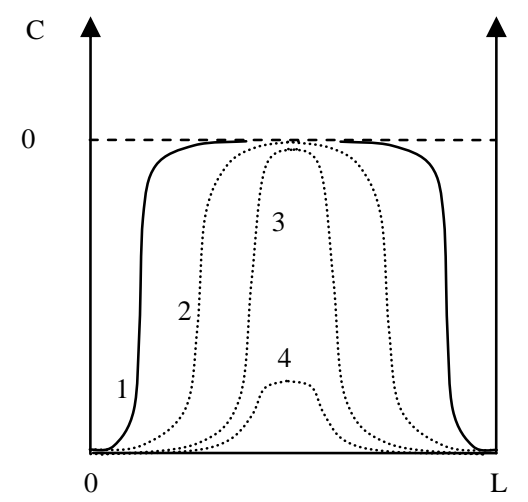


Figure 7.9. Real shape of the concentration profile in plasticization, in the example illustrated by Figure 7.7, at times $0<t_{1}<t_{2}<t_{3}<t_{4}$

\subsection{Chemical ageing - general aspects}

\subsubsection{The two large families of chemical ageing processes}

It is important to distinguish the processes which only affect lateral groups, without changes to the macromolecular skeleton, from processes which alter the macromolecular skeleton. Indeed, the first processes do not affect mechanical behavior (at reasonable conversion ratio), whereas the second processes greatly affect the mechanical behavior, even at low conversion ratio.

\subsubsection{Processes affecting lateral groups}

Halogenation and sulfonation processes etc., are likely to replace various hydrogen groups carried in the chain by chlorine atoms, $\mathrm{SO}_{3}$ groups ect..., but such processes are rarely encountered in an ageing context. In contrast, oxidation processes are very frequent. These processes also affect the macromolecular skeleton, but for now we will only deal with the consequences of altering lateral groups, e.g.:

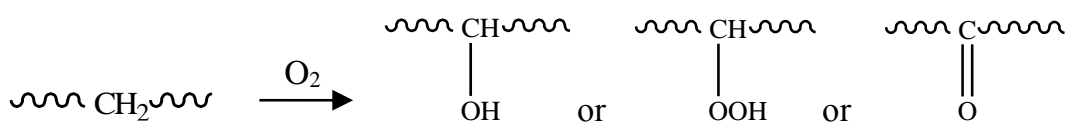

A hydrocarbon group, only slightly polar, is transformed into an oxygenated polar group (ketone), or even a very polar group (alcohol). If this transformation occurs in a matrix which is initially rich in polar groups, there will be few consequences on the physical properties. On the other hand, if it occurs in a matrix which is only slightly polar (polyolefin, hydrocarbon elastomers), then resultant changes in polarity may have significant consequences on all the physical properties linked to this characteristic, particularly dielectric permittivity, refraction index, surface energy, and wettability.

Some processes lead to the formation of colored species. In the case of PVC, such as sequential elimination of hydrogen chloride:

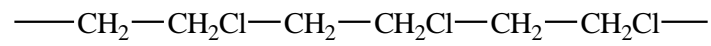


$\rightarrow \mathrm{HCl}+-\mathrm{CH}=\mathrm{CH}-\mathrm{CH}=\mathrm{CH}-\mathrm{CH}=\mathrm{CH}-$

Sequences of more than five to seven conjugated double bonds absorb in the visible spectrum and absorption spreads towards large wavelengths when the number of conjugated double bonds increases. The material will appear yellow-brown or purple according to the distribution of the conjugated sequence lengths. These species have very high molar extinction coefficients, up to more than $10^{5} 1 . \mathrm{mol}^{-1} \mathrm{~cm}^{-1}$. The coloring appears at low, or even very low, conversion ratio.

In polymers made up of aromatic nuclei, their oxidation leads to quinoid species which absorb near UV and violet. These materials (polystyrene, polycarbonate, PET, polyesters cross-linked by styrene, epoxides, etc.) undergo a degree of yellowing over ageing.

The oxidation of saturated polymers (PE, PP, for example) may also lead to colored species if the material initially contains traces of metallic impurities which can potentially form colored complexes with some oxidation products, such as carbonyls.

Lastly, some stabilization processes, particularly with aromatic amines or phenols, are also likely to create strongly colored species which can be distinguished from the species already present on the polymers, by the fact that they can be extracted by solvents.

\subsubsection{Macromolecular skeleton modification process}

Two types of processes can be distinguished here (Figure 7.10).

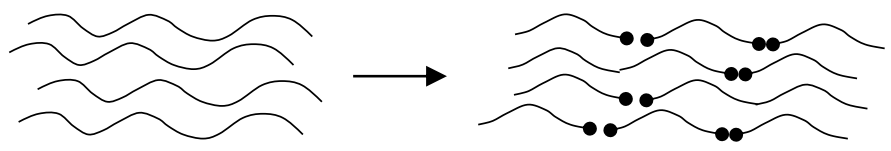

Random chain scission

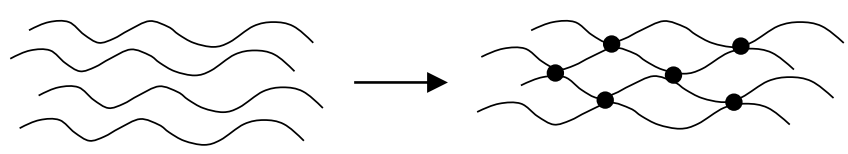

Random chain welding (crosslinking) 
Figure 7.10. Diagram representing two types of macromolecular skeleton modification processes

Of course, the two process types can coexist. If $\mathrm{s}$ and $\mathrm{x}$ are the respective numbers (moles) of scission and crosslinking events per mass unit, the average molar mass in number $M_{n}$ (initial value $M_{n 0}$ ) variation and weight (initial value $M_{w 0}$ ) is given by the following system of equation:

$$
\begin{aligned}
& \frac{1}{M_{n}}-\frac{1}{M_{n 0}}=s-x \\
& \frac{1}{M_{w}}-\frac{1}{M_{w 0}}=\frac{s}{2}-2 x
\end{aligned}
$$

We are able to see that if $\mathrm{s}>4 \mathrm{x}$, chain scission prevails.

On the other hand, if $s<4 x$, crosslinking will prevail.

So long as the material stays $100 \%$ soluble, then this system of equations enables us to determine $\mathrm{s}$ and $\mathrm{x}$ from average molar masses $\mathrm{M}_{n}$ and $\mathrm{M}_{\mathrm{w}}$. But if crosslinking prevails, the material bypasses the gelation point and an insoluble fraction appears. We can then apply the Charlesby theory:

$$
\mathrm{w}_{\mathrm{s}}+\mathrm{w}_{\mathrm{s}}^{1 / 2}=\frac{\mathrm{s}}{2 \mathrm{x}}+\frac{1}{\mathrm{M}_{\mathrm{w} 0} \mathrm{x}}
$$

where $\mathrm{w}_{\mathrm{s}}$ is the soluble fraction.

This equation is easy to exploit if $\mathrm{s}$ and $\mathrm{x}$ vary in a linear way with time, which is generally the case in radiochemical ageing at relatively high dose rates.

\subsection{Consequences of chain scission}

As seen in Chapter 5 (section 5.2.5), fracture properties of a linear polymer vary enormously around a critical molar mass $\mathbf{M}_{\mathrm{C}}$ '. We can then expect that the fracture properties of an initially ductile/tough polymer, drop significantly when its molar mass reaches value $\mathrm{M}_{\mathrm{C}}$. Let us consider a chain scission process at constant rate $\mathrm{v}$ :

$$
\mathrm{s}=\mathrm{vt}
$$


In the absence of crosslinking:

$$
\mathrm{s}=\frac{1}{\mathrm{M}_{\mathrm{n}}}-\frac{1}{\mathrm{M}_{\mathrm{n} 0}}
$$

Therefore:

$$
M_{n}=M_{n 0}\left(\frac{1}{1+v M_{n 0} t}\right)
$$

Let us consider an example where $\mathrm{M}_{\mathrm{n} 0}=100 \mathrm{~kg} \cdot \mathrm{mol}^{-1}, \mathrm{v}=10^{-4}$ mol.kg.j $\mathrm{j}^{-1}$ and $\mathrm{M}_{\mathrm{C}}{ }^{\prime}=$ $20 \mathrm{~kg} \cdot \mathrm{mol}^{-1}$. The evolution of $\mathrm{M}_{\mathrm{n}}$ and the ultimate elongation are represented in Figure 7.11 .

These results call for the following remarks:

- where the chain scission reaction occurs at constant rate, the molar mass varies hyperbolically;

$-\mathrm{M}_{\mathrm{n}}$ varies monotonously whereas the ultimate elongation drops catastrophically when $\mathrm{M}_{\mathrm{n}}=\mathrm{M}_{\mathrm{C}}$;

- embrittlement occurs when the number of chain scissions is:

$$
\mathrm{s}_{\mathrm{c}}=\frac{1}{\mathrm{M}_{\mathrm{C}}^{\prime}}-\frac{1}{\mathrm{M}_{\mathrm{n} 0}}=0,04 \mathrm{~mol} \cdot \mathrm{kg}^{-1}
$$




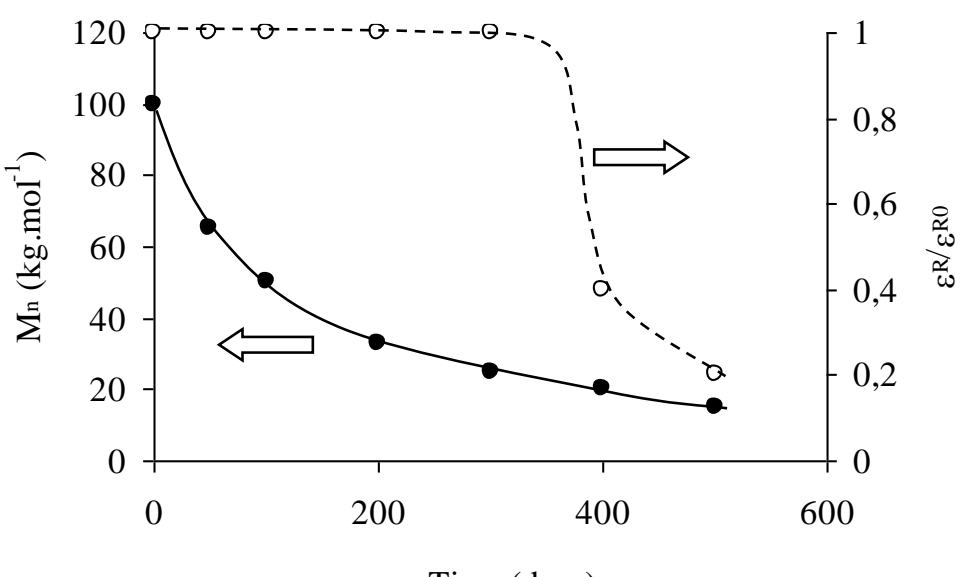

Time (days)

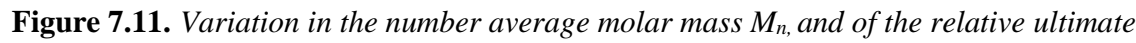
elongation $\varepsilon_{r} / \varepsilon_{r}$ in a polymer subjected to ageing by random chain scission at a rate of $10^{-4}$ moles scissions per kg per day

As an example, in a polymer such as polyamide 11 or PET, the concentration in monomer units is 5 mol. $\mathrm{kg}^{-1}$. In other words, embrittlement occurs at a very low conversion ratio, which is sometimes difficult or impossible to detect by spectrochemical means. The elastic and yielding properties are practically unaffected at such conversion ratio. We understand, then, that embrittlement caused by ageing is an important aspect of research. Whatever the importance of other usage properties, no application can tolerate the geometric integrity of the samples being damaged by crack growth.

In some cases of superficial ageing, localized embrittlement may create a network of microcracks without a notable influence on the total fracture behavior. However, microcracking will change the appearance of the surface which may also have an economic impact in applications where questions of aesthetics are important.

In networks (vulcanized elastomers, thermosets), random chain scission can destroy chains which are elastically active. Typically, at low conversion ratio, for a quasi ideal network: 


$$
v=v_{0}-\mathrm{s}
$$

where $v$ and $v_{0}$ are the concentrations in elastically active chains, before and after ageing respectively, and $\mathrm{s}$ is the number of chain cuts. Let us remember that $\mathrm{v}$ can be determined by measurements of the elasticity modulus in rubbery state:

$v=\frac{\mathrm{G}}{\mathrm{RT} \rho} \quad$ (G: shear modulus)

therefore:

$$
\mathrm{s}=\frac{1}{\mathrm{RT} \rho}\left(\mathrm{G}_{0}-\mathrm{G}\right)
$$

Chain cuts can decrease the elastomer's modulus. On the other hand, they do not directly influence the thermosets modulus in glassy state.

Fracture properties tend to drop catastrophically, but the structure/property relationships are still relatively unknown in this domain.

\subsection{Crosslinking consequences}

For exclusive crosslinking (no chain scission), $M_{w}$ and $M_{n}$ increase, the polymolecularity index $\mathrm{p}=\mathrm{M}_{\mathrm{w}} / \mathrm{M}_{\mathrm{n}}$ also increases, $\mathrm{p}$ and $\mathrm{M}_{\mathrm{w}}$ diverge at the gelation point which corresponds to:

$$
\mathrm{x}_{\mathrm{g}}=\frac{1}{2 \mathrm{M}_{\mathrm{w} 0}}
$$

Here, we also see that gelation relates to a very weak conversion ratio. Two active sites are needed to make a crosslink, therefore the transformation rate at gelation point is $y_{\mathrm{g}}=\frac{1}{\mathrm{M}_{\mathrm{w} 0}}$. In polyethylene, for example, for $\mathrm{M}_{\mathrm{w} 0}=100 \mathrm{~kg} \cdot \mathrm{mol}^{-1}$ we would obtain that $\mathrm{y}_{\mathrm{g}}=10^{-2}$ mol. $\mathrm{kg}^{-1}$ whereas the concentration in potentially reactive sites $\left(-\mathrm{CH}_{2}-\right)$ is approximately 7,000 times greater. Of course, certain properties, particularly flow properties in molten state, change well before the gelation point. In particular, viscosity in molten state rapidly increases and the Newtonian plateau tends to disappear. 
Elongation at break gradually decreases, whereas the stress at break increases, at least in an elastomer's initial ageing phase. Where thermosets are concerned, we know that $\mathrm{T}_{\mathrm{g}}$ increases and that the ductility tends to decrease.

\subsubsection{Diffusional phenomena in chemical ageing}

Oxidation and hydrolysis (two frequent modes in chemical ageing) involve penetrating a small reactive molecule $\left(\mathrm{O}_{2}, \mathrm{H}_{2} \mathrm{O}\right)$ from the environment in the material. We can define two characteristic times - one being diffusion, the other a chemical reaction - for a simplified approach to the problem:

- in the case of diffusion, characteristic time can be defined by:

$\mathrm{t}_{\mathrm{D}}=\frac{\mathrm{L}^{2}}{\mathrm{D}}$ where $\mathrm{L}$ is the sample's thickness and $\mathrm{D}$ the diffusion coefficient of the molecular reactant;

- in the case of the reaction, we can use the following definition:

$\mathrm{t}_{\mathrm{R}}=\frac{\mathrm{C}}{\mathrm{v}_{\mathrm{C}}}$ where $\mathrm{C}$ is the equilibrium concentration of the reactant in the polymer, and $\mathrm{v}_{\mathrm{c}}$ is the rate of the reactant consumption by the reaction in the sample's superficial layer where the reactant's concentration is effectively $\mathrm{C}$.

The equality of the two times is achieved for:

$\mathrm{t}_{\mathrm{D}}=\mathrm{t}_{\mathrm{R}}$ meaning that $\mathrm{L}_{\mathrm{C}}=\left(\frac{\mathrm{DC}}{\mathrm{v}_{\mathrm{C}}}\right)^{1 / 2}$

- if the sample's thickness is $\mathrm{L} \ll \mathrm{L}_{\mathrm{C}}$, then diffusion is quick enough in relation to the reaction, in order to saturate the sample in its entire volume at any time;

- if the sample's thickness is $\mathrm{L}>\mathrm{L}_{\mathrm{C}}$, then any molecular reactant is consumed in a layer with a thickness of the order of $\mathrm{L}_{\mathrm{C}}$ and the sample's core is not degraded.

By comparing the total degradation rates of samples which differ in thickness, we can build the graph in Figure 7.12 which enables us to determine $\mathrm{L}_{\mathrm{C}}$. 


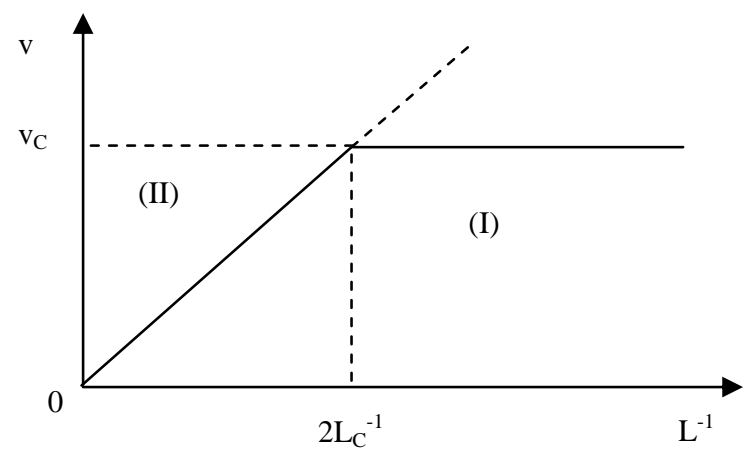

Figure 7.12. Shape of degradation rate variations with the reverse of the sample's thickness

Two regimes can be distinguished: the regime which is not controlled by diffusion (I) where the (total) degradation rate is independent of the thickness, and the regime which is controlled by diffusion (II) where the (total) degradation rate is in proportion to the reverse thickness since the thickness of the degraded layer $\left(\mathrm{L}_{\mathrm{C}}\right)$ is independent of the whole sample thickness. The boundary value is $2 \mathrm{~L}_{\mathrm{C}}$ if the molecular reactant penetration is carried out by the two sides of the sample, which is often the case.

For a more rigorous and detailed approach to the problem, the relationship $\mathrm{v}_{\mathrm{C}}=$ $\mathrm{v}(\mathrm{C})$ expressing the reactant's consumption rate according to its concentration in the case of a homogeneous reaction $\left(\mathrm{L}<<\mathrm{L}_{\mathrm{C}}\right)$ must be established. The variation rate of the reactant's local concentration is, then, given by the equation:

$$
\frac{\partial \mathrm{C}}{\partial \mathrm{t}}=-\mathrm{v}(\mathrm{C})+\mathrm{D} \frac{\partial^{2} \mathrm{C}}{\partial \mathrm{x}^{2}}
$$

where $\mathrm{x}$ is the spatial coordinate (in the direction perpendicular to the sample's surface) and D is the molecular reactant's diffusion coefficient.

Many authors assume rapid installation of a stationary state such as:

$$
\frac{\partial \mathrm{C}}{\partial \mathrm{t}}=0 \quad \text { therefore } \quad \frac{\partial^{2} \mathrm{C}}{\partial \mathrm{x}^{2}}=\mathrm{v}(\mathrm{C})
$$

Therefore, we assume that the molecular reactant has a stationary concentration profile in the sample: $\mathrm{C}=\mathrm{f}(\mathrm{x})$, which is a result of solving the above differential equation. 
In hydrolysis processes, for example, we can generally say that:

$\mathrm{v}_{\mathrm{C}}=\mathrm{KC}$ (pseudo first order process)

In oxidation processes, $\mathrm{v}_{\mathrm{C}}$ varies with $\mathrm{C}$ according to a pseudo-hyperbolic curve which can be approximate by:

$$
\mathrm{v}_{\mathrm{C}}=\frac{\alpha \mathrm{C}}{1+\beta \mathrm{C}}
$$

where $\alpha$ and $\beta$ are parameters which can be clarified according to the rate constants of elementary processes which are constitutive of the radical oxidation chain reaction.

Numerical solutions of kinetic equations and reaction-diffusion coupling equations free us from simplifying hypotheses, particularly those of a stationary state which is often difficult to justify.

Let us return to the scaling relationship of the simplified approach to the problem:

$$
\mathrm{L}_{\mathrm{C}}=\left(\frac{\mathrm{DC}}{\mathrm{v}_{\mathrm{C}}}\right)^{1 / 2}
$$

C generally hardly varies with temperature.

D generally obeys the Arrhenius law: $D=D_{0} \exp \left(-\frac{E_{D}}{R T}\right)$

For $\mathrm{v}_{\mathrm{C}}$, we may also consider the Arrhenius law to be obeyed in a first approach: $\mathrm{v}_{\mathrm{C}}=\mathrm{v}_{\mathrm{C} 0} \exp \left(-\frac{\mathrm{E}_{\mathrm{C}}}{\mathrm{RT}}\right)$.

We can see that $\mathrm{L}_{\mathrm{C}}$ should also obey the Arrhenius law:

$$
\mathrm{L}_{\mathrm{C}}=\mathrm{L}_{\mathrm{C} 0} \exp \left(-\frac{\mathrm{E}_{\mathrm{L}}}{\mathrm{RT}}\right) \text { with } \mathrm{E}_{\mathrm{L}}=\frac{1}{2}\left(\mathrm{E}_{\mathrm{D}}-\mathrm{E}_{\mathrm{C}}\right)
$$


With regard to thermal ageing, we generally have $E_{C}>E_{D}$, so that $L_{C}$ is a decreasing function of temperature (Figure 7.13).

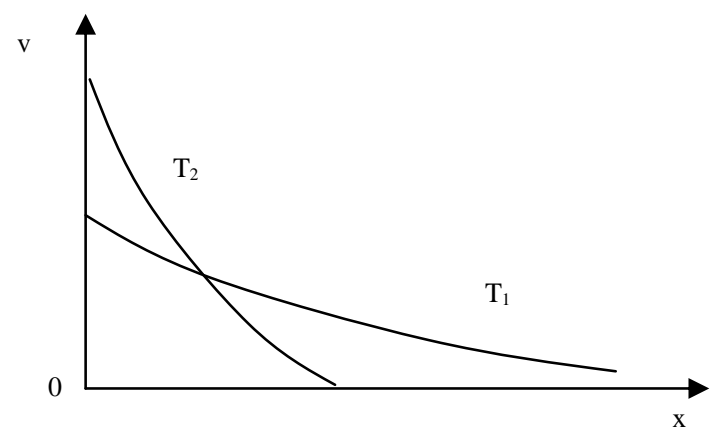

Figure 7.13. Diagram representing degradation profiles (thermo-oxidation) at two different temperatures: $T_{1}<T_{2}$ and at a sensitively equal total degradation rate

In the case of ageing by irradiation, $\mathrm{D}$ and $\mathrm{C}$ are independent of radiation intensity $\mathrm{I}$, whereas $\mathrm{v}_{\mathrm{C}}$ can be approximately obtained by $\mathrm{v}_{\mathrm{C}} \alpha \mathrm{I}^{\alpha}$. It results that

$$
\mathrm{L}_{\mathrm{C}} \alpha \mathrm{I}^{-\alpha / 2}
$$

$\mathrm{L}_{\mathrm{C}}$ decreases slowly with I because $\alpha$ is generally lower than unity $(\alpha=1 / 2$ in the simplest models).

The fact that the thickness of the degraded layer is generally a decreasing function of the "aggressiveness" of the exposure conditions may go against intuition, but it is a fact which has been checked many times.

\subsubsection{Consequences of superficial deterioration on usage properties}

Of course, surface properties (color, wettability, etc) are not dependant on the degradation gradients. On the other hand, these gradients may play an important role in terms of mechanics.

Schematically, a polymer sample (initially ductile/tough and homogeneous) is gradually transformed into two layers by ageing. The inner layer remains ductile/tough, but the superficial layer is brittle and cracks easily. A crack which starts in the superficial layer will quickly make its way into the superficial/inner layer 
interface. It will either be blunted, or it will propagate, leading to a break in the sample (Figure 7.14).

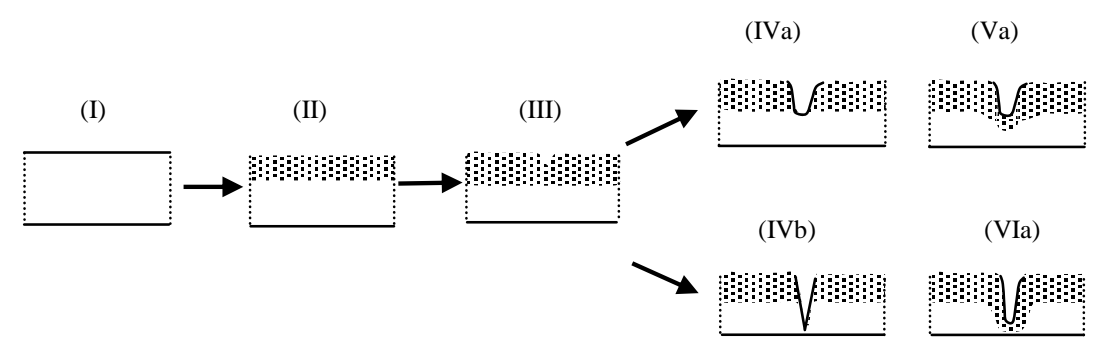

Figure 7.14. Diagram representing possible crack growth modes of a sample subjected to surface level ageing. The dots symbolize degradation: I is the initial sample, II is the aged sample before the embrittlement threshold, III is the sample which is close to the embrittlement threshold, IVa is a sample with blunted crack, with the crack making its way to the degraded/non-degraded interface, IVb shows the crack crossing the degradation front, Va and $\mathrm{Vb}$ show the progression of the degradation front at the top of the crack.

As a first approach, we may consider that the weakened superficial layer is equivalent to a notch of the same depth. Fracture mechanics (Griffith 1921) enable us to predict that there is a critical notch depth, which will not initiate crack growth if it is not reached. This critical depth depends on the material's strength, which depends on crack propagation rate.

Therefore we expect that a very rapid ageing process, leading to a low level of thickness of the oxidized layer, changes fracture behavior comparatively less than a slower ageing process. This has been checked many times in experiments.

\subsubsection{Towards a non-empirical lifetime prediction}

Ageing is a complex phenomenon but which can be broken down into elementary mechanisms which obey simple kinetic laws (Arrhenius law, proportionality of rate to light intensity, etc.). However, the "target" of chemical ageing is the molecular scale structure, but the usage properties depend on higher scale structures [AUD 07]. Moving away from these reports, we can develop a strategy for predicting nonempirical lifetimes, represented in the following diagram (Figure 7.15). 
Time

Structure at molecular scale

Structure at macromolecular scale

Structure at macroscopic scale (skin-core)

Use properties

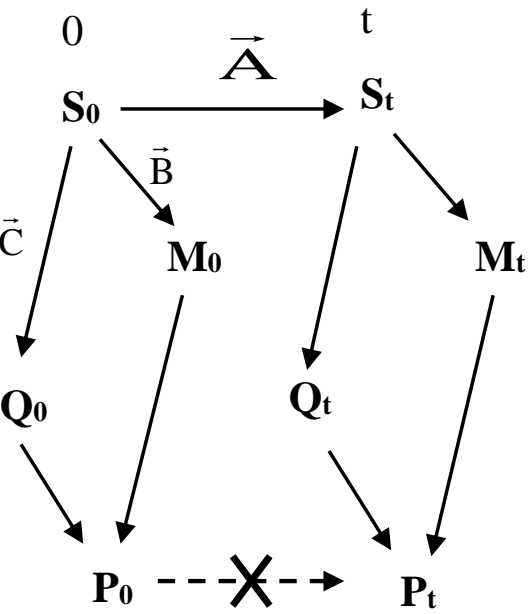

Figure 7.15. Diagram illustrating the strategy for predicting non-empirical lifetime

Vector $\overrightarrow{\mathrm{A}}$ represents a chemical kinetics model, showing the evolution of the material to the molecular scale. Vector $\overrightarrow{\mathrm{B}}$ symbolizes the path from the molecular scale to the macromolecular scale. This process involves knowledge of the elementary event of scission/crosslinking, and reaction statistics. Vector $\overrightarrow{\mathrm{C}}$ represents reactiondiffusion coupling. All the other vectors show relationships coming from polymer physics.

For different reasons (mechanism hyper-complexity, gaps in polymer physics, etc.) some of the relationships involved in this diagram cannot be translated in mathematical terms. On the other hand, achieving all the procedure steps in a nonempirical way may constitute an unrealistic research program from an economical point of view. It will be, then, a matter of injecting a minimum of empiricism into the model so that it works, but by making the conducted hypotheses as clear as possible.

From this, the chosen strategy seems to be the best possible compromise between the need for scientific rigor, which guarantees the reliability of the prediction, and economic constraints. 


\subsubsection{Oxidation - general aspects}

For the majority of practical cases in thermal, photochemical or radiochemical ageing, the main cause for ageing is oxidation of the polymer by interaction with oxygen in the atmosphere.

In all cases oxidation results from radical chain reactions and the kinds of ageing mentioned above, they only differ by initiation (in mechanistic terms)

The standard mechanistic scheme, drawn up by an English team in the 1940s [BOLL 46], is the following:
(I) polymer $(\mathrm{PH}) \rightarrow \mathrm{P}^{\circ}$
( $\left.\mathrm{r}_{\mathrm{i}}\right) \quad$ (Initiation)
(II) $\mathrm{P}^{\circ}+\mathrm{O}_{2} \quad \rightarrow \quad \mathrm{PO}_{2}{ }^{\circ}$
$\left(\mathrm{k}_{2}\right) \quad$ (Propagation)
(III) $\mathrm{PO}_{2}^{\circ}+\mathrm{PH} \rightarrow \mathrm{Per}+\mathrm{P}^{\circ}$
$\left(\mathrm{k}_{3}\right) \quad$ (Propagation)
(IV) $\mathrm{P}^{\circ}+\mathrm{P}^{\circ} \rightarrow$ Inactive products $\left(\mathrm{k}_{4}\right)$
(Termination)
(V) $\mathrm{P}^{\circ}+\mathrm{PO}_{2}{ }^{\circ} \rightarrow$ Inactive products $\left(\mathrm{k}_{5}\right)$
(Termination)
(VI) $\mathrm{PO}_{2}^{\circ}+\mathrm{PO}_{2}^{\circ}$
$\rightarrow \quad$ Inactive products $\left(\mathrm{k}_{5}\right)$
(Termination)

As we have seen, initiation may be thermal, photochemical or radiochemical. It can be the result of a reaction which directly involves a non-degraded part of the polymer (radiochemical) or a reaction product, particularly a peroxide or hydroperoxide (Per).

Propagation involves two chemical processes, the second one (III) regenerating radical $\mathrm{P}^{\circ}$ involved in the first one (II). Adding $\mathrm{O}_{2}$ to the radicals (II) is very fast $\left(\mathrm{k}_{2}\right.$ $\sim 10^{8}$ à $\left.10^{9} \mathrm{~L} \cdot \mathrm{mol}^{-1} \cdot \mathrm{s}^{-1}\right)$. The reaction between peroxyl radicals $\left(\mathrm{PO}_{2}{ }^{\circ}\right)$ and the polymer is much slower ( $\mathrm{k}_{3} \sim 0.01$ to $10 \mathrm{~L} \cdot \mathrm{mol}^{-1} . \mathrm{s}^{-1}$, typical values at room temperature). $\mathrm{PO}_{2}{ }^{\circ}$ radicals can act abstracting hydrogen or adding to double bonds. In the first case, the product Per is a hydroperoxide ( $\mathrm{POOH})$. In the second, it is a peroxide (POOP).

The terminations (when there are no stabilizers) are bimolecular. Two radicals are deactivated mutually. We have, then:

$$
\mathrm{k}_{4}>\mathrm{k}_{5}>\mathrm{k}_{6}
$$

When there is excess oxygen (low thickness sample, high $\mathrm{O}_{2}$ pressure, low initiation rates), radicals $\mathrm{P}^{\circ}$ are quickly transformed into $\mathrm{PO}_{2}{ }^{\circ}$ by reaction II. The probability of their reacting by other means becomes very low, and the scheme is simplified as follows in the case of propagation by hydrogen abstraction, for example:

(I) polymer $+\mathrm{O}_{2} \rightarrow \mathrm{PO}_{2}{ }^{\circ}$ 
$\begin{array}{llll}\text { (III) } \mathrm{PO}_{2}{ }^{\circ}+\mathrm{PH}+\mathrm{O}_{2} & \rightarrow & \mathrm{PO}_{2} \mathrm{H}+\mathrm{PO}_{2}^{\circ} & \left(\mathrm{k}_{3}\right) \\ \text { (VI) } \mathrm{PO}_{2}{ }^{\circ}+\mathrm{PO}_{2}{ }^{\circ} & \rightarrow & \text { Inactive products }+\mathrm{O}_{2} & \left(\mathrm{k}_{5}\right)\end{array}$

We can therefore distinguish two important cares:

Reaction (I) is carried out at constant rate $\mathrm{r}_{\mathrm{i}}$ (radiochemical initiation). Therefore, a stationary state is quickly established, and the oxidation products gather at constant rate (figure 7.16).

We can easily show that products from initiation and termination are formed at a rate which is proportional to $r_{i}$. On the other hand, hydroperoxide (propagation product) is formed at rate $\mathrm{v}(\mathrm{POOH})=\mathrm{k}_{3}[\mathrm{PH}]\left(\frac{\mathrm{r}_{\mathrm{i}}}{2 \mathrm{k}_{6}}\right)^{1 / 2}$ (proportional to $\sqrt{\mathrm{r}_{\mathrm{i}}}$ ).

Oxygen is absorbed at rate: $\mathrm{v}_{0 \mathrm{k}}=\frac{\mathrm{r}_{\mathrm{i}}}{2}+\mathrm{k}_{3}[\mathrm{PH}]\left(\frac{\mathrm{r}_{\mathrm{i}}}{2 \mathrm{k}_{6}}\right)^{1 / 2}$.

Reaction (I) is the decomposition of peroxides or hydroperoxides formed during propagation. Initiation can be written as:

$$
\begin{array}{ll}
\delta \mathrm{POOH} \rightarrow \alpha \mathrm{P}^{\circ}+\beta \mathrm{PO}_{2}{ }^{\circ} \quad \text { with } \quad \text { if } \delta=1, \alpha=2 \text { and } \beta=0 \\
& \text { if } \delta=2, \alpha=1 \text { and } \beta=1
\end{array}
$$

When $\delta=2$ (more common at temperatures higher than $150^{\circ} \mathrm{C}$ ), the kinetics are comprised of an induction period followed by a strong auto-acceleration preceding a steady state (Figure 7.16).

This type of reaction can be called a "closed loop" reaction because it produces its own initiator: hydroperoxide.

The kinetic analysis of the two process types show that kinetic behavior depends, in both cases, on two main factors: one which is extrinsic (relating to factors which are external to the polymer's structure), for instance the initiation rate constant $\mathrm{k}_{\mathrm{i}}$ or initiation rate $r_{i}$ which depend of radiation intensity in photo or radiochemical ageing. The other factor is intrinsic e.g. only dependent of polymer structure, for instance the ratio $\frac{\mathrm{k}_{3}}{\sqrt{\mathrm{k}_{6}}}$ which characterizes the polymer oxidability. 


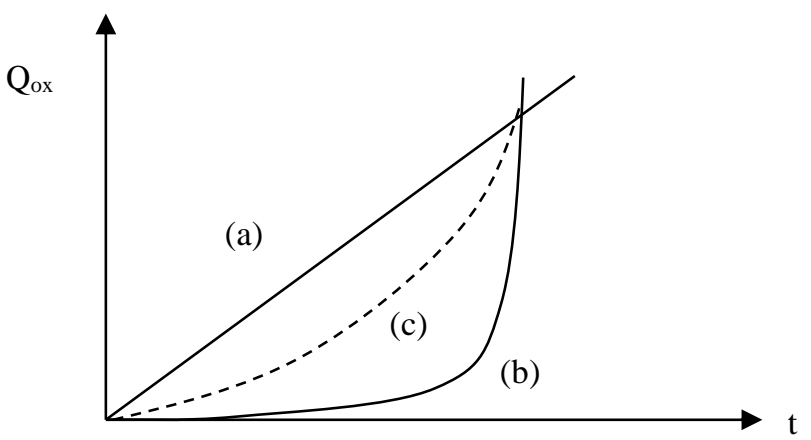

Figure 7.16. Shape of the kinetic curves of oxidation (a) for constant rate initiation (radiochemical ageing) (b) initiation by bimolecular decomposition $(\delta=2)$ of hydroperoxides (thermal ageing). In cases of unimolecular initiation $(\delta=1)$ of hydroperoxide $(c)$ initial autoacceleration is more progressive (some cases of photochemical ageing).

For "closed loop" processes, where $[\mathrm{POOH}]_{0}$ and $[\mathrm{POOH}]_{\infty}$ are the initial and steady state hydroperoxide concentrations respectively, the ratio $\frac{[\mathrm{POOH}]_{\infty}}{[\mathrm{POOH}]_{0}}$ determine the amplitude of the auto-acceleration effects.

Polymers which do not contain $\mathrm{CH}$ bonds (polytetrafluorethylyene) or polymers only containing aromatic $\mathrm{CH}$ (PEEK, poly(ether sulfones), polyimides, etc.) are generally stable under oxidation. Polymers only containing methyls (polydimethylsiloxane) or methyls and methylenes (poly(methyl methylacrylate), polycarbonate, polyethylene) are moderately stable. Polymers containing tertiary $\mathrm{CH}$ (polypropylene), $\mathrm{CH}$ in $\alpha$ of heteroatoms (polyoxymethylene) or allylic $\mathrm{CH}$ (polydienic elastomers) are relatively instable. Let us note that it is a matter of a comparison of relatively little practical use because another (physical) factor plays an important role: oxygen diffusivity. The diffusivity is notably higher in elastomers than in glassy polymers. In other words, with equal reactivity, these latter will seem more stable because the thickness of their oxidized superficial layer will be lower.

Another potentially important factor: the property sensitivity to chemical acts of oxidation. For example, polypropylene becomes brittle in a number of chain scissions which are about 10 times smaller than for an amorphous polymer. According to mechanical criteria, it will seem 10 times less stable than an amorphous polymer with the same reactivity.

Despite these reservations, the classification of groups according to the following decreasing order of stability is completely valid: 


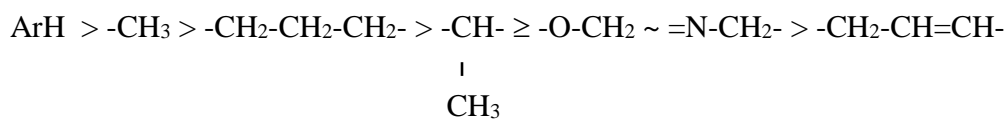

\subsubsection{Stabilization}

Chain reactions, like radical oxidation, particularly when they produce their own intiation, have a major disadvantage in terms of practice: small problems may lead to big effects, in light of the strong auto-accelerating character of these reactions. But this disadvantage turns into an advantage when we plan to produce stabilization by additives (antioxidants). Indeed, since the reaction starts slowly and auto-accelerates, a small quantity of the stabilizers when adequately chosen may be enough to efficiently inhibit the process, a possibility which does not exist for step by step reactions, such as hydrolysis for example.

It generally seems difficult to change the propagation process. Yet, we can slow down initiation, for example, with stabilizers which destroy the hydroperoxides by non-radical means (sulfurs, phosphites). Or we can accelerate termination with stabilizers capable of capturing radicals $\mathrm{P}^{\circ}$ or $\mathrm{PO}_{2}{ }^{\circ}$ (phenols, aromatic amines, hindered amines, nitroxyl radicals, etc.) In polyolefins, we may reach an efficient stabilization with stabilizing mass fractions lower than $0.5 \%$. In polydienic elastomers, stabilizers can be used in concentrations higher than $1 \%$. The most common appreciation method of stabilizer efficiency consists of determining the induction time at high temperatures (Figure 7.17).

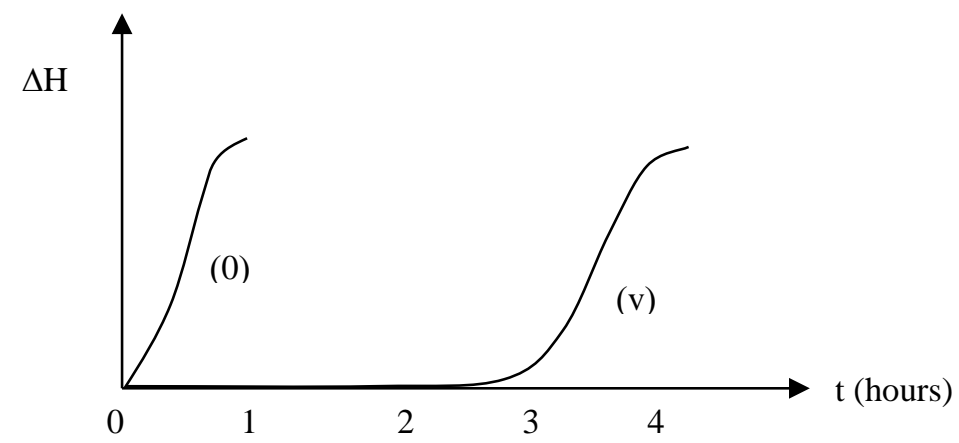

Figure 7.17. Shape of thermograms at $190^{\circ} \mathrm{C}$ (raise in temperature under nitrogen, oxygen is admitted in the cell when the thermal equilibrium has been reached): a non-stabilized polyethylene (0), the same polyethylene stabilized by $0.3 \%$ of a phenol-phosphite combination.

It is important to note that the effectiveness of stabilizers also depends on physical factors, in particular: 
- solubility in the polymer. If the solubility level is low, the concentration level necessary for good levels of stabilization may not be reached. We may note that many stabilizers are comprised of long alkyl chains for instance in distearylthiodipropionate:

$$
\mathrm{S}-\left[\mathrm{CH}_{2}-\mathrm{CH}_{2}-\underset{\mathrm{O}}{\mathrm{C}}-\mathrm{O}-\mathrm{C}_{18} \mathrm{H}_{37}\right]_{2}
$$

Thermal antioxidant hydroperoxide decomposor;

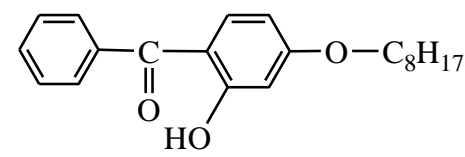

UV absorber;

-diffusivity in the polymer. If the diffusivity level is too high, stabilizer loss through migration might decrease its efficiency. To reduce diffusivity, we can increase the molar mass (alkyl chain grafting, polymer stabilizers, etc.).

In addition to these significant factors, the choice of stabilizer must take other characteristics into account, such as:

- compatibility with the considered use (color, smell, toxicity, etc.);

- interaction with the environment. For example, phenolic stabilizers create highly colored species in the presence of nitrogen oxides; some hindered amines react with certain biocides used in farming, etc.;

- interaction with other polymer additives. For example, organic sulfides are not compatible with metals because they create highly colored metal sulfides.

Not all interactions are problematic, some stabilizers have an increased level of efficiency when combined with another additive. We can call this a secondary stabilizer. This is the case for combination of zinc and calcium soaps in PVC. Synergy mechanisms are very varied. In phenol-hydroperoxide decomposer systems, synergy is essentially the result of a kinetic effect due to the fact that each stabilizer exerts a favorable strain on a different step of the oxidation chain reaction. For $\mathrm{Ca} / \mathrm{Zn}$ soaps in PVC, the "primary" stabilizer is the zinc soap, but the PVC-Zn reaction generates zinc chloride which is a powerful catalyst for the degradation of PVC. The role of Ca soap 
is to eliminate zinc chloride by a double decomposition reaction which generates $\mathrm{Zn}$ soap.

\subsection{Thermochemical ageing}

\subsubsection{Intrinsic thermal stability}

In the absence of oxygen, polymers will decompose through their own instability, with this being controlled by thermochemical factors. Generally, it is a matter of radical processes initiated by a break in the weakest bond (meaning the bond with the weakest dissociation energy).

Aromatic bonds C-C and C-H and C-F bonds are among the most stable $\left(\mathrm{E}_{\mathrm{d}} \sim 500\right.$ $\left.\mathrm{kJ} . \mathrm{mol}^{-1}\right)$. Polymers which only carry this type of bond are known as "thermostable".

The more the carbons are substituted, the less stable the aliphatic bonds $\mathrm{C}-\mathrm{C}$ become:

$$
-\mathrm{CH}_{2}-\mathrm{CH}_{2-}>\mathrm{CH}_{2}-\mathrm{CH}\left(\mathrm{CH}_{3}\right)->\mathrm{CH}_{2}-\mathrm{C}\left(\mathrm{CH}_{3}\right)_{2-}
$$

Polymers containing tetrasubstituted carbons (polyisobutylene, PMMA, poly $(\alpha$ methylstyrene), etc.) are particularly unstable.

However, total thermal stability does not only depend on bond weakness, but also on the tendency (or not) of primary radicals to initiate a chain propagation process. In polyethylene, for example, the radicals are easily deactivated by disproportionation:

$$
-\mathrm{CH}_{2}-\mathrm{CH}_{2}-\mathrm{CH}_{2}-\mathrm{CH}_{2-} \rightarrow-\mathrm{CH}_{2}-\mathrm{CH}_{2}{ }^{\circ}+{ }^{\circ} \mathrm{CH}_{2}-\mathrm{CH}_{2-} \rightarrow-\mathrm{CH}_{2}-\mathrm{CH}_{3}+\mathrm{CH}_{2}=\mathrm{CH}-
$$

In polyisobutylene, as in other polymers which contain a quaternary carbon, and in polyoxymethylene, the radicals begin a "zip" process to eliminate the monomer:

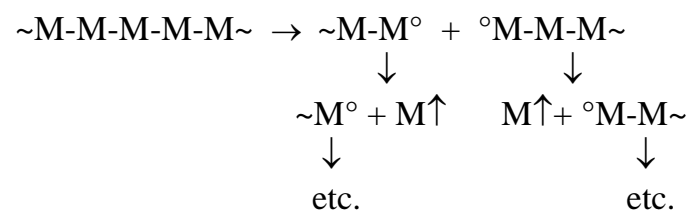


This process is called "depolymerization". Polymers which depolymerize are those which possess the lowest thermostabilities.

PVC is subject to a lateral group "zip" elimination reaction:

$$
\begin{aligned}
\sim \mathrm{S}-\mathrm{CH}_{2}-\mathrm{CHCl}-\mathrm{CH}_{2}-\mathrm{CHCl} \rightarrow \sim \mathrm{S}-\mathrm{CH}= & \mathrm{CH}-\mathrm{CH}_{2}-\mathrm{CHCl} \sim \\
\downarrow & +\mathrm{HCl} \\
\sim & \mathrm{S}-\mathrm{CH}=\mathrm{CH}-\mathrm{CH}=\mathrm{CH} \sim \\
+\mathrm{HCl} & \text { etc. }
\end{aligned}
$$

$\mathrm{S}$ is a structural irregularity (for example, double bond formed during polymerization) which makes the first elimination act easier.

For step by step processes (such as polyethylene thermal degradation) there is no known method of stabilization.

On the other hand, for chain processes (depolymerization, sequential elimination of $\mathrm{HCl}$, etc.) it is possible to plan stabilization by:

- removing "weak points" through chemical modification during synthesis (blocking terminal alcohols in POMs) or by a reaction with a stabilizer during processing (PVC stabilizers);

- disfavoring propagation by an adequate comonomer, in the case of POM, for example:

\section{$-\mathrm{CH}_{2}-\mathrm{O}-\mathrm{CH}_{2}-\mathrm{O}-\mathrm{CH}_{2}-\mathrm{O}-\mathrm{CH}_{2}-\mathrm{CH}_{2}-\mathrm{O}-\mathrm{CH}_{2}-\mathrm{O}-\mathrm{CH}_{2}-\mathrm{O}-\mathrm{CH}_{2}-$}

Inserting dimethylenic units into the chain by copolymerization can slow down the depolymerization process. The POM copolymers can be distinguished from "homopolymers" by their melting point which is lower by 10 to $20^{\circ} \mathrm{C}$.

\subsubsection{Oxidative ageing}

Bonds present in industrial polymers possess dissociation energies which are rarely lower than $270 \mathrm{~kJ} \cdot \mathrm{mol}^{-1}$. Oxidation by atmospheric oxygen makes peroxides and hydroperoxides appear (as we have seen) whose dissociation energy of the bond $-\mathrm{O}-\mathrm{O}$ - is in the order of $150 \mathrm{~kJ} \mathrm{~mol}^{-1}$. These groups decompose at temperatures which are clearly lower than for the groups carried by the monomer unit. This is why thermal ageing of polymers is controlled, in the vast majority of cases, by oxidation - at least in usage conditions. As we have seen, stability then depends above all on the reactivity of $-\mathrm{C}-\mathrm{H}$ bonds via the ratio: $\frac{\mathrm{k}_{3}}{\sqrt{\mathrm{k}_{6}}}$ 
Thermo-oxidations at moderate temperatures $\left(<150^{\circ} \mathrm{C}\right)$ have the following common characteristics:

- an induction phenomenon. The induction period is a decreasing function of temperature. Its apparent activation energy in the absence of a stabilizer is generally in the order of $100 \pm 20 \mathrm{~kJ}_{\text {. mol }}{ }^{-1}$. These values are higher in the presence of stabilizers;

- when there is an oxygen excess (no termination of $\mathrm{P}^{\circ}$ radicals), oxidation often results in a predominance of chain scission particularly related to the $\beta$ scission of alkoxyl radicals:

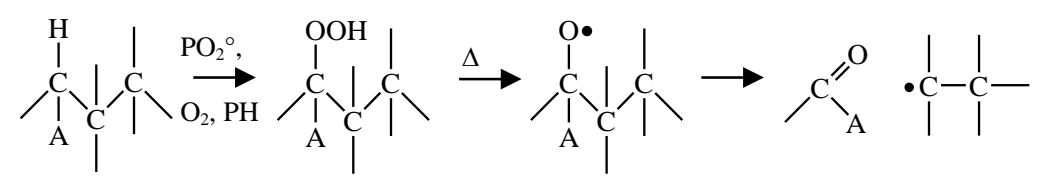

Crosslinking only prevails when the polymer carries double bonds onto which the radicals can easily be added (polybutadiene);

- in thick objects, thermo-oxidation is controlled by oxygen diffusion. The thickness of the oxygenated layer is a decreasing function of temperature;

- oxidation results in the accumulation of stable oxygenated groups: carbonyls, ethers, alcohols, etc., which may titrated at relatively low concentration by IR spectrophotometry. However, in general, molecular mass measurements are more sensitive;

- although in a first approach, oxidation can be considered as a hydrogen substitution by heavier oxygenated groups, it generally leads to mass loss related to the elimination of volatile fragments (Figure 7.18).

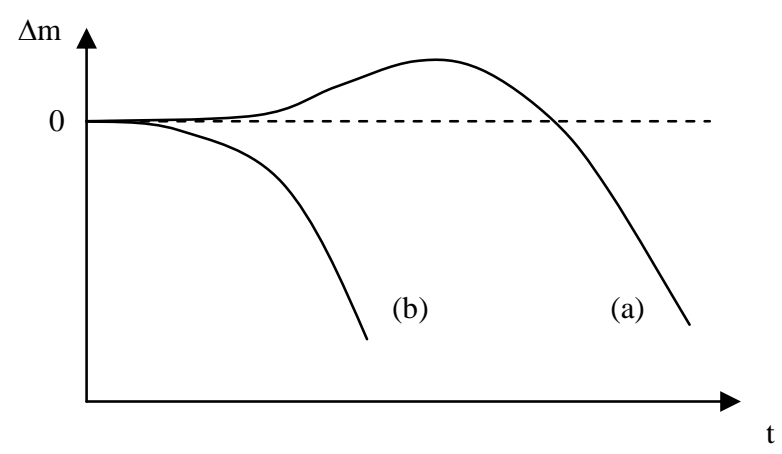


Figure 7.18. Shape of mass variations during thermal oxidation. (a) polymer with a relatively low initiation rate. Mass gain prevails during the induction period. Mass loss prevails after the mass gain has ended; (b) polymer with a relatively high initiation rate: mass loss prevails as exposure begins.

Polypropylene and polybismaleimides for example, belong to the family (a) (Figure 7.18). Polyoxymethylene and epoxides crosslinked by amines rather belong to family (b). In all polymers oxidizing at low temperatures (polyolefins, polydienes), antioxidants generally have a noticeable effect, even spectacular, on the induction periods. This effect is a lot less important, even not important at all, when polymers oxidize at higher temperatures (thermostable polymers, particularly).

\subsubsection{Lifetime in thermal ageing}

The lifetime versus temperature curves take the shape represented in Figure 7.19.

With regard to low temperatures (of practical interest for users) we conventionally define a duration of 5000, 20,000 or 100,000 hours depending on the application, and we define the corresponding temperature on the curve, which we call maximum continuous operating temperature $\left(\mathrm{T}_{\mathrm{mu}}\right)$.

Typically $50^{\circ} \mathrm{C} \leq \mathrm{T}_{\mathrm{mu}} \leq 100^{\circ} \mathrm{C}$ for commodity polymers, such as PVC, PP, ABS, etc. and $250^{\circ} \mathrm{C} \leq \mathrm{T}_{\mathrm{mu}} \leq 300^{\circ} \mathrm{C}$ for thermostable polymers, such as polysulfones, polyimides, etc. All industrial polymers are in between these two limits.

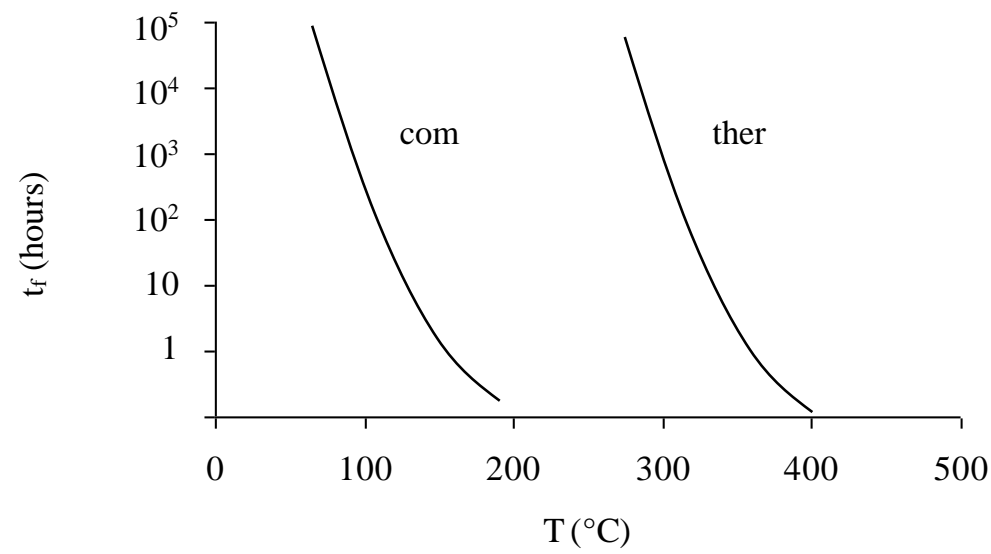


Figure 7.19. Lifetime (time to embrittlement) versus temperature. Curve shape for a commodity polymer (com) and for a thermostable polymer (therm).

For high temperatures (of practical interest for processing practionners), knowing the "maximum thermal stability" is necessary because this "maximum" constitutes one of the "processability window" boundaries (see section 5.4). Certainly, for a given polymer, these boundaries are moved according to the severity of the end-of-life criteria and the efficiency of the stabilizers.

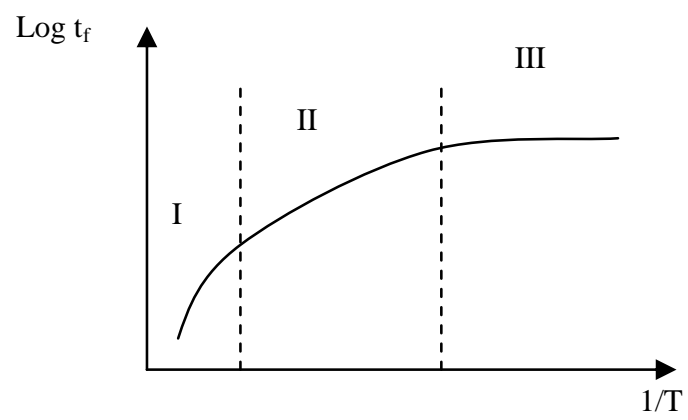

Figure 7.20. Shape of the Arrhenius graph for lifetime in a wide temperature interval

From very early on, we have tried to give a mathematical form to curves $t_{F}=f(T)$. In the 1940s, the Arrhenius law was first proposed [DAK 48]. In its simplest form, it is written: $\log t_{F}=A+\frac{B}{T}$ which allows for linear extrapolation.

This method has given way to diverse standards and recommendations. The $\mathrm{T}_{\mathrm{mu}}$ shown in industrial polymer technical notices are always obtained in this way. However, when we carry out experiments in a wide temperature interval, it is not rare to find that we obtain graphs with the shape of Figure 7.20.

We observe a general tendency for the apparent activation energy (B) to increase when the temperature increases, with three or more domains which are easy to distinguish:

- domain I: oxidation is controlled by diffusion, the polymer is subjected to thermolytic degradation. 
- domain II: this is the domain of "closed loop" oxidation, with an apparent activation energy in the order 80 to $120 \mathrm{~kJ} \cdot \mathrm{mol}^{-1}$ in the absence of stabilizers, 120 to $200 \mathrm{~kJ} \cdot \mathrm{mol}^{-1}$ in the presence of stabilizers;

- domain III: this is also a closed loop oxidation domain, but at low temperatures the termination reactions are controlled by diffusion of radicals and the apparent activation energy tends to decrease.

This type of behavior has been observed on many different occasions, for example in polyethylene and elastomers.

Kinetic modeling allows us to take this phenomenon into account and to carry out lifetime predictions which are more realistic than simple linear extrapolation from system II.

\subsection{Photochemical ageing}

\subsubsection{Introduction: solar radiation}

For light radiation to induce photochemical processes in a polymer, first of all it must be absorbed, and then this absorption must lead to photoexcited species which are capable of giving way to irreversible chemical processes. In solar radiation on the earth surface, (Figure 7.21) radiation with the lowest wavelengths essentially belonging to the UV component ( $300 \mathrm{~nm} \leq \lambda \leq 400 \mathrm{~nm}$ ) are potentially capable of inducing such processes. 


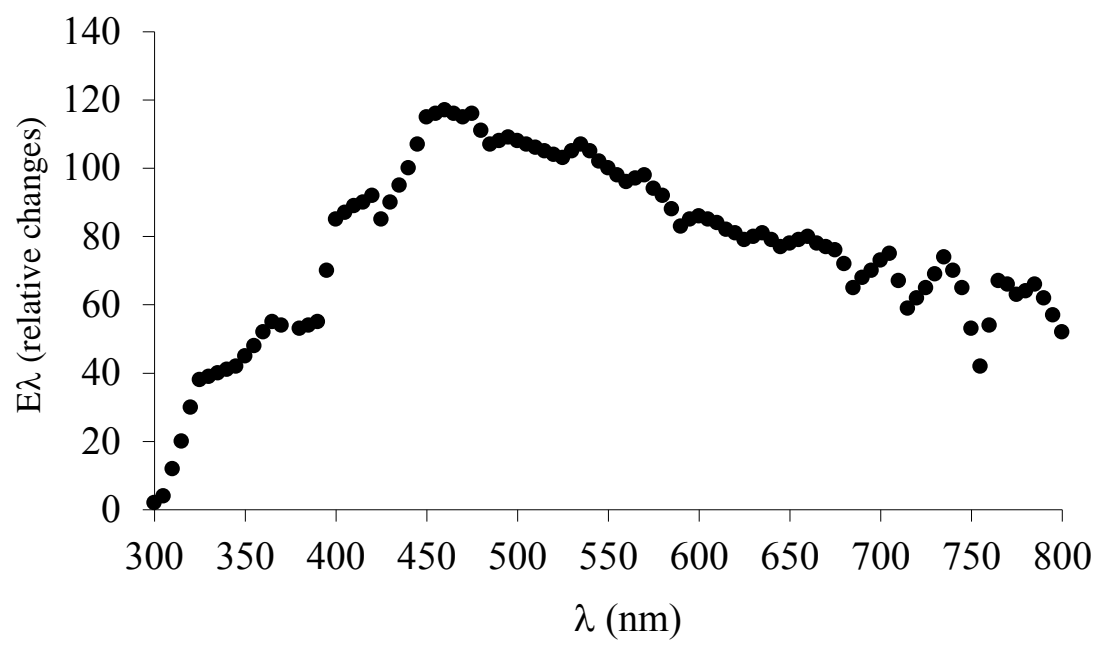

Figure 7.21. Solar radiation. Spectral distribution according to ICI E1.3.1 D.65 $(I C I=$ International commission on illumination $)$

Total solar energy, in the order of $300 \mathrm{~kJ} \mathrm{~mol}^{-1}$ in the North of Europe and 800 kJ.mol ${ }^{-1}$ in desert tropical areas, in France between $~ 360 \mathrm{~kJ} . \mathrm{mol}-1$ in the North and $460 \mathrm{~kJ} . \mathrm{mol}^{-1}$ on the Mediterranean. UV energy varies between around $2 \%$ (in the winter) and 7\% (in the summer) of the total energy in the temperate zone, where the seasonal variation tends to increase with latitude.

Cloud cover, altitude-latitude and surface orientation are at the root of local variations which are sometimes difficult to model. The first difficulty encountered in the study of photochemical ageing is the complexity of the fluctuations of all kinds of "photoactive" solar energy.

7.5.2. "Intrinsic" photochemistry and photo-oxidation; photo-oxidation and thermooxidationthermo-oxidation

Some industrial polymers are "intrinsically photoreactive". In other words, carefully purified and irradiated under nitrogen by solar UV $(\lambda \geq 300 \mathrm{~nm})$, they are subjected to photochemical ageing.

The most well-known case is aromatic polymers comprised of ester groups, particularly polycarbonates. They are subjected to "photo-fries" rearrangement. 


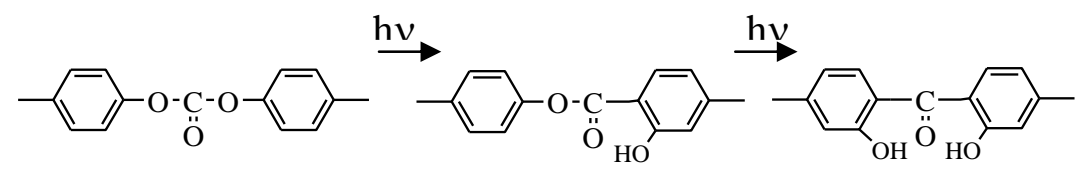

The species which result from this reaction strongly absorb in the near UV and violet, which leads to the following consequences:

- the material is subject to yellowing;

- the photo-transformed layer strongly absorbs UV. Therefore it plays the role of a protective screen for the under layers. The photo-transformation is therefore selfretarded.

As this reaction does not modify the macromolecular skeleton, there are no consequences on the polymer's mechanical behavior.

These examples aside, most industrial polymers do not present intrinsic photoreactivity in solar UV. Irradiated in the inert atmosphere, they evolve either very little or not at all. However, the presence of atmospheric oxygen completely changes the behavior because the "primary" products (hydroperoxides) and some "secondary" products (ketones) of radical oxidation are greatly photoreactive and the photoexcitation which is created from free radicals capable of initiating new radical chains, hence the strongly self-accelerated character from photo-oxidation.

Thus, polymers which are transparent in UV in pure state (polyethylene, polypropylene, polydienes, etc.) can be catastrophically photodegraded because they still contain impurities or structural irregularities capable of initiating the reaction in a "closed loop".

As photo-oxidation is nearly always accompanied by chain cuts from hydroperoxide or ketonic photolysis, this leads to embrittlement: 


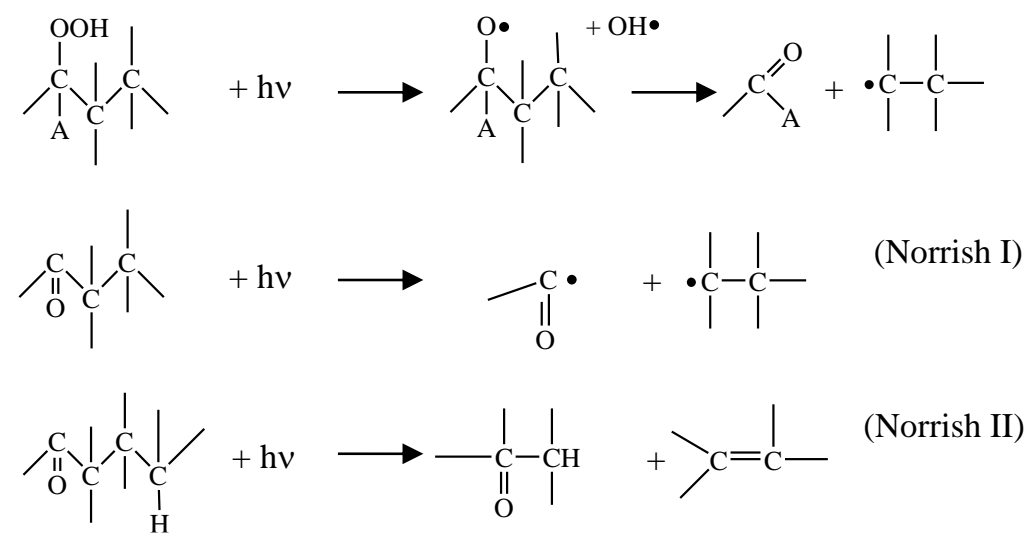

Photo-oxidation presents many similarities with thermo-oxidation at low temperatures. The radical chain propagation mechanism is the same, however it differs by two characteristics:

- initiation by $\mathrm{POOH}$ decomposition is unimolecular, whereas it is often bimolecular in the case of thermo-oxidation. Initial autoacceleration is more gradual in photo than in thermal ageing;

- the POOH decomposition rate by photochemical means is higher (under normal irradiation conditions) than in thermal ageing. The induction period is therefore very short, even non-existent. However, if we sufficiently reduce the irradiation intensity, we observe an induction period.

If the test temperature is high enough and the exposure time long enough, initiation of POOH by thermal decomposition may coexist with photochemical initiation. Thus, if we express the oxidation rate by an approximate relationship:

$$
\mathrm{v}=\mathrm{KI}^{\alpha} \exp \left(\frac{\mathrm{E}}{\mathrm{RT}}\right)
$$

We observe that $\alpha$ tends to increase with I and decrease with T, whereas $\mathrm{E}$ tends to increase with $\mathrm{T}$ and decrease with $\mathrm{I}$. These dependencies demonstrate well the nonvalidity of this type of relationship.

\subsubsection{Photostabilisation. $U$ V screens}

Since as a first approximation the initiation rate is proportional to the absorbed light intensity, the first possible means of stabilization consist of decreasing the light intensity by incorporating into the polymer strong UV absorbing additives. 
These additives may be pigments such as carbon black or titanium dioxide (white) glow. This latter must be surface treated to inhibit the well-known photocatalytic effect. These pigments are efficient in concentrations of few percents.

(Organic) plastosoluble additives, greatly absorbing in the 300-400nm interval, and transparent in the visible spectrum can also be used (figure 7.22).

These stabilizers, generally used in mass concentrations of 0.1 to $1 \%$, are only really efficient in thick objects (typically $\geq 0.1 \mathrm{~mm}$ ). The most frequently used are hydroxybenzophenones, hydroxybenzotriazoles, benzylidene malonates and substituted acrylonitriles. We will note that the first two families contain a phenolic group potentially capable of playing an antioxidant role.

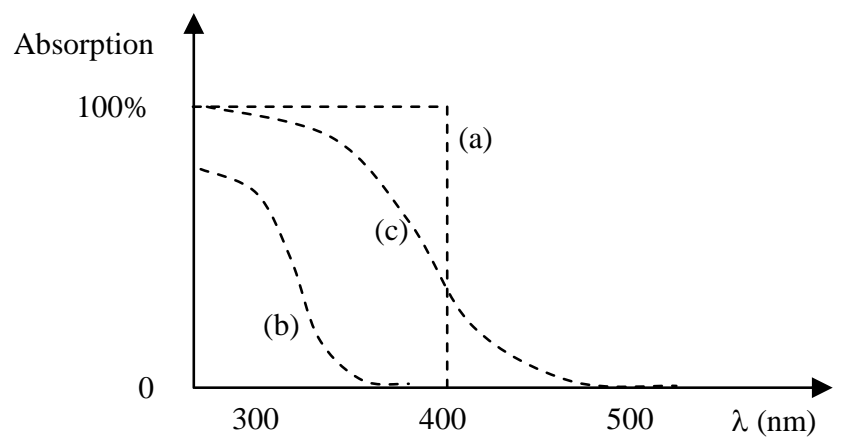

Figure 7.22. Absorption spectrum of UV absorbers: (a) ideal UV absorber; (b) UV absorber with limited protective power but colorless; (c) efficient UV absorber but yellow (it absorbs at $\lambda>400 \mathrm{~nm}$ in violet)

We also use radical scavengers (Tetramethylpiperidine type hindered amines) which may react with practically all species involved in the oxidation chain reaction: $\mathrm{PO}_{2}{ }^{\circ}, \mathrm{P}^{\circ}$ and perhaps $\mathrm{POOH}$. Nitroxyl radicals, very useful in termination reactions, are important intermediates in stabilization processes:

$$
=\mathrm{N}-\mathrm{O}^{\circ}+\mathrm{P}^{\circ} \rightarrow=\mathrm{N}-\mathrm{O}-\mathrm{P}
$$

These stabilizers may also play the role of an antioxidant in the thermo-oxidation processes. 


\subsubsection{Towards a lifetime prediction in photoageing}

For now, the generally used solution is based upon carrying out accelerated ageing tests constituting the best compromise between an exposure duration as low as possible and a simulation as close as possible to natural ageing. It is hypothesized (although not expressed) that if it is a "good" simulation, then there is a "good correlation" between the results for natural and accelerated ageing. This hypothesis has no scientific or logic grounding.

However, where a non-empirical alternative may exist for thermo-oxidation, carrying this out for photo-oxidation requires much more delicacy, as the following additional problems may arise:

- distribution of initiation in the sample's thickness does not simply depend on the reaction/diffusion coupling, but also on the screen effect of absorbent species, and this effect may vary as the reaction conversion increases;

- in principle, we know how to write kinetic equations for monochromatic irradiation, but the path for polychromatic irradiation is very complex;

- as already seen, daily, seasonal and geographical fluctuations in solar irradiation are difficult to model.

None of these problems is irresolvable, but due to the fact that researchers dedicate their time to analytical aspects and mechanisms, and that experts in the field are happy with just simulation tests, means that there has been no satisfactory solution propose to date.

\subsection{Hydrolytic ageing}

\subsubsection{Introduction}

Hydrolytic ageing involves an ageing process resulting from the chemical interaction of a polymer with water. The main chemical act is a hydrolysis process which can be schematized in the following way:

$$
\sim \mathrm{A}-\mathrm{B} \sim+\mathrm{H}_{2} \mathrm{O} \rightarrow \sim \mathrm{A}-\mathrm{OH}+\mathrm{HB} \sim
$$

In the most important examples in terms of practice, the broken bond is a molecular skeleton bond. Each hydrolysis process is therefore a chain scission. In all the chain scission cases, hydrolysis leads to polymer embrittlement at a low conversion rate, hence the interest in this type of ageing.

For a water molecule to react with a group in the middle of a sample, this molecule must penetrate the said sample. In doing so, this will change the sample's properties 
and lead to physical ageing (see section 7.2). We know cases of "pure" physical ageing by water absorption for hydrophilic but not hydrolysable polymers. However, there is no such thing as "pure" chemical ageing; all hydrolytic ageing is accompanied by plasticization, swelling, etc., which are characteristics common to physical ageing. We recognize this latter kind of ageing by the fact that it is reversible (so long as the material in undamaged): drying will restore the original material properties. In contrast, chemical ageing is irreversible (Figure 7.23).

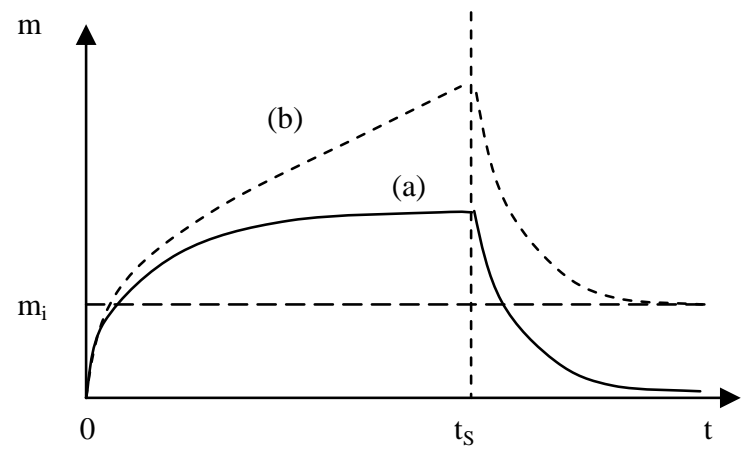

Figure 7.23. Shape of mass variations in a sample placed in a humid atmosphere $\left(t<t_{S}\right)$ and a dry atmosphere $\left(t>t_{s}\right)$. (a) "pure" physical ageing: the mass gain curve tends towards equilibrium, we find the original mass after a drying process. The absorption and desorption rates are equal (when there is no damage). (b) sample under hydrolysis (without extracting small molecules). Each hydrolysis process leads to a mass gain of $18 \mathrm{~g} / \mathrm{mol}$. The mass in dry state increases irreversibly. NOTE: The mass in dry state may increase, decrease or vary in a non-monotone manner (see further)according to chemical ageing cases.

\subsubsection{Quasi irreversible hydrolysis}

Polycarbonate, linear saturated polyesters, unsaturated polyesters crosslinked by styrene will hydrolyze until high conversion rates are reached, without any significant rate decrease being observed. For these polymers, we may consider (at least as a first estimation) that hydrolysis is irreversible. This leads us to write:

$$
\mathrm{E}+\mathrm{W} \rightarrow \mathrm{Ac}+\mathrm{Al}
$$

where $\mathrm{E}$ is the ester group, W the water molecule, Ac and A1 respectively the acid and alcohol groups from hydrolysis. Each act of hydrolysis leads to one chain scission. We can write, then, in a system not controlled by diffusion that: 


$$
\frac{\mathrm{ds}}{\mathrm{dt}}=\mathrm{k}[\mathrm{E}][\mathrm{W}]=\mathrm{k}\left(\left[\mathrm{E}_{0}\right]-\mathrm{s}\right)[\mathrm{W}]
$$

It should be noted that $\mathrm{s}$ is the number of chain scission, $[\mathrm{W}]$ represents the water concentration in the polymer and $\mathrm{k}$ is the rate constant.

Since embrittlement occurs at low conversion rates, we have $s<<[E]_{0}$ and hydrolysis hardly changes the polymer hydrophilic properties. Therefore:

$$
\frac{\mathrm{ds}}{\mathrm{dt}}=\mathrm{k}[\mathrm{W}] \mathrm{E}_{0} \approx \mathrm{constant}
$$

meaning:

$$
\mathrm{s}=\mathrm{K} . \mathrm{t} \quad \text { where } \mathrm{K}=\mathrm{k}[\mathrm{W}][\mathrm{E}]_{0}
$$

The end-of-life criteria is the ductile-brittle transition occurring at $M_{n}=M_{c}$ '.

The number of chain scissions $\mathrm{S}_{\mathrm{F}}$ at the end life is:

$$
\mathrm{s}_{\mathrm{F}}=\frac{1}{\mathrm{M}_{\mathrm{c}}{ }^{\prime}}-\frac{1}{\mathrm{M}_{\mathrm{n} 0}}
$$

The $t_{\mathrm{F}}$ lifetime is therefore:

$$
\mathrm{t}_{\mathrm{F}}=\frac{\mathrm{s}_{\mathrm{F}}}{\mathrm{K}}=\left(\frac{1}{\mathrm{M}_{\mathrm{c}}{ }^{\prime}}-\frac{1}{\mathrm{M}_{\mathrm{n} 0}}\right) \frac{1}{\mathrm{k}[\mathrm{W}][\mathrm{E}]_{0}}
$$

where $\mathrm{k}$ obeys the Arrhenius law: $\mathrm{k}=\mathrm{k}_{0} \cdot \exp (-\mathrm{E} / \mathrm{RT})$ and $[\mathrm{W}]$ is determined by the equality of chemical potentials of water in the medium and in the water.

For a material with little hydrophilic properties:

- $[\mathrm{W}]=[\mathrm{W}]_{\mathrm{S}}$ (saturated water concentration in the material) in the case of immersion in pure water; 
$-[\mathrm{W}]=[\mathrm{W}]_{\mathrm{S}} \frac{\mathrm{HR}}{100}$ (where HR is the relative hygrometry) in the case of exposure in humid atmospheres.

This means that in all cases:

$$
\mathrm{t}_{\mathrm{F}}=\frac{1}{[\mathrm{E}]_{0}}\left(\frac{1}{\mathrm{M}_{\mathrm{c}}{ }^{\prime}}-\frac{1}{\mathrm{M}_{\mathrm{n} 0}}\right)\left[\frac{1}{\mathrm{k}_{0} \exp \left(-\frac{\mathrm{E}}{\mathrm{RT}}\right)}\right]\left[\frac{100}{\mathrm{~W}_{\mathrm{S}} \cdot \mathrm{HR}}\right]
$$

where $\mathrm{HR}=100$ for immersion in pure water.

Therefore, we have a non-empirical relationship which connects lifetime to three factors: one which represents the effect of the polymer structure, another which shows the effect of temperature, and a final factor which represents the effect of the medium composition.

Structure-reactivity relationships are relatively well known in this field. For example, where polyesters are concerned, for a given diol such as propylene glycol, we obtain, in order of increasing stability:

maleate $<$ orthophtalate $<<$ acrylate

In the same way, for a given diacid, for example a maleate:

ethylene glycol < propylene glycol < neopentyl glycol

\subsubsection{Reversible hydrolysis}

In some cases, such as for polyamide 11 , hydrolysis is self retarded as soon as exposure begins and the molecular mass rapidly stabilizes, which indicates that a reversible process exists:

$$
\mathrm{E}+\underset{\mathrm{k}_{\mathrm{H}}}{\mathrm{W}} \leftrightarrows \mathrm{Ac}+\mathrm{Am}
$$

where Ac and Am respectively indicate the acid and amine resulting from hydrolysis. Here, $\mathrm{E}$ is the amide. In most cases, initial acid and amine concentrations are equal $[\mathrm{Ac}]_{0}=[\mathrm{Am}]_{0}$. 
We can then say that:

$$
\frac{\mathrm{ds}}{\mathrm{dt}}=\mathrm{k}_{\mathrm{H}}\left([\mathrm{E}]_{0}-\mathrm{s}\right)[\mathrm{W}]-\mathrm{k}_{\mathrm{R}}\left([\mathrm{Ac}]_{0}+\mathrm{s}\right)\left([\mathrm{Am}]_{0}+\mathrm{s}\right)
$$

It is easy to show that the molar mass at equilibrium $\mathbf{M}_{\mathrm{ne}}$ is given by:

$$
M_{n e}=\left(\frac{k_{R}}{k_{H}[E]_{0}[W]_{0}}\right)^{1 / 2}
$$

The molar mass decreases according to a pseudo exponential law with a time constant of:

$$
\mathrm{Z}=\frac{\mathrm{M}_{\mathrm{ne}}}{2 \mathrm{k}_{\mathrm{R}}}
$$

Of course, embrittlement occurs if the critical molar mass $M_{C}$ ' is higher than $M_{n e}$, which is the case for PA11, at least at high temperatures. Integrating the above differential equation allows us, in principle, to determine the lifetime by using a nonempirical way.

\subsubsection{Role of solutes in water}

Hydrolysis proceeds by an ionic mechanism which is likely to be accelerated by acids, bases or both. However, as ionic species are not soluble in the polymer, only non-dissociated species are likely to penetrate the material and to exert their catalytic role.

Merdas et al. [MER 02] summarize the effect of different factors in the following expression on hydrolysis rate $\mathrm{V}$ :

$$
\mathrm{V}=\mathrm{K}(1+\gamma[\mathrm{AH}])^{1 / 2}
$$

where $[\mathrm{AH}]$ is the acid concentration in the polymer, $\gamma$ a parameter essentially related to the acid dissociation constant, and $\mathrm{K}$ a prefactor which comprises the different factors which influence hydrolysis in pure water. The catalysis effect becomes noticeable when, typically:

$\gamma[\mathrm{AH}] \geq 0.1$ 
Catalysis is important under the following conditions:

- weak organic acid (benzoic acid, for example): $\gamma$ is weak but $[\mathrm{AH}]$ is strong because acid is soluble in the polymer ;

- strong acid ( $\mathrm{HC} 1$, for example): $\gamma$ is strong but in moderate $\mathrm{pH}$ levels $(\mathrm{pH} \geq 2$, for example), the acid is completely dissociated, the ions are not soluble in the polymer, therefore $[\mathrm{AH}] \sim 0$, the effect is weak. At low $\mathrm{pH}$ levels, on the other hand, a significant fraction of the acid is not dissociated and can penetrate the polymer. Thus, the acid's catalytic effect may be very strong. Additionally, the acid displaces the equilibrium, the reaction becomes quasi irreversible, and very weak molar masses may be reached.

Let us add to this that if the catalytic effect of the solute is very strong, the hydrolytic attack will then be controlled by the water diffusion. We then have a very deep degradation in a very thin superficial layer, and the sample is destroyed by erosion (polyester fibers in soda, for example).

We must not forget that water generally contains dissolved oxygen and disinfectants (chlorine, for example) which may play the role of radical initiators. Oxidation may be superposed onto hydrolysis. In the case of PA11 for example, autoclave hydrolysis tests must be carried out in an inert atmosphere because when $\mathrm{T}$ $\geq 100^{\circ} \mathrm{C}$ the oxygen's contribution to chain scission is significant.

\subsubsection{Secondary effects of hydrolysis - Composites}

\subsubsection{Osmotic crack growth}

For unsaturated polyester fiberglass composites (boats, swimming pools), variations in mass related to water absorption have a very distinct shape which can be shown in Figure 7.24.

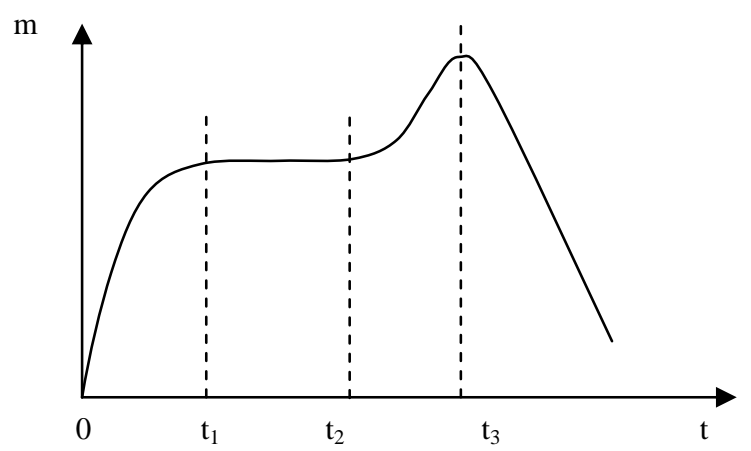


Figure 7.24. Shape of variations in mass in thin $(<1 \mathrm{~mm})$ samples of composites subjected to osmotic crack growth

The reason for this behavior has been explained as follows: the initial phase is simply water absorption by the classic dissolution-diffusion mechanism. At $t_{1}$, the system reaches a sorption equilibrium.

However, water reacts with the polymer. As the polymer is rich in chain ends, the chain scissions on dangling chains create a set of small organic molecules (monomers, oligomers). When these small molecules (which are more polar than the polymer) reach their solubility threshold, they demix and form liquid micro-pockets with high hydrophilicity, at time $t_{2}$.

The presence of water in these micro-pockets generates osmotic pressure, therefore the resulting stress state tends to propagate cracks from the micro-pockets which constitute initiating flaws. Between $t_{2}$ and $t_{3}$ the mass increases because the cracks let in more and more water.

At $t_{3}$, the cracks coalesce and the sample empties its solutes contained in the dip. The mass decreases rapidly.

In composites, cracks form in a subcutaneous layer and propagate in parallel to the surface, hence the formation of blisters, well known by users.

The aptitude of a given material generating blisters in the presence of water is essentially related to the quantity of small molecules which gather in the matrix, which depends on three factors:

- the concentration of initially present molecules (particularly the initiation system of polymerization and its reaction products);

- the initial concentration of free chain ends (as strong as the initially unsaturated polyester's molar mass was low);

- the polymer's hydrolysis rate (which creates new chain ends).

The effect of these various factors has been vigorously checked in experiements [GAU 99]. 


\subsubsection{Interfacial hydrolysis}

In some cases of composites based on hydrolysis resistant matrices (vinyl ester, non-hydrolysable thermoplastics), wet ageing leads to a degradation of mechanical properties which cannot be attributed to a matrix-water interaction. Microscopic or mechanical analyses (interlaminar shear resistance for example) demonstrate that a fiber-resin decohesion exists.

Additionally, it seems that the material stability in given conditions narrowly depends on the nature of the coupling agents used. Therefore, we are displaying a case of hydrolysis reactions affecting the fiber/resin interphase.

If there are many methods of experimentation to demonstrate this phenomenon in a qualitative way, there is no method (to our knowledge) of indisputably quantifying the number of chemical events responsible for the observed evolution.

For the moment, it is not possible to carry out a fine kinetic analysis for this type of ageing.

\subsubsection{Stabilization}

With hydrolysis being a step by step mechanism where each chemical event is independent from the previous ones, there is no real useful method of stabilization. In some cases, PET geotextile fibers for example, some manufacturers propose fibers coated with a polymer layer with a very low hydrophilicity (PE, PTFE). However, water diffusion in these coatings is relatively quick and we do not know whether the stabilizing effect is particularly impressive.

It might be the case eventually, though, when the fiber is located in a particularly aggressive environment (e.g. basic) because it will then significantly slow down the superficial attack. At the moment we lack hindsight to fully understand the efficiency of these solutions, but we may doubt its total efficiency.

\subsection{Conclusion}

We have tried to present the main ageing processes in organic materials which are likely to be found in the civil engineering domain. This presentation has aimed for neither exhaustivity nor depth of analysis. Yet, with the basic elements for comprehension, the reader will be able to find the following messages implicitly:

- There is not one single mode of ageing, but many modes likely to superpose and interact. 
- Ageing is not a mysterious phenomenon which obeys its own laws, but a more or less complex set of physical and chemical mechanisms, each obeying already known laws.

- Vigorous research in the last 50 years has allowed for an identification of most of these elementary mechanisms. The main point of this research is the development of kinetic models able to simulate the behavior of such systems whose complexity (e.g. processes involving many tens of elementary reactions, with reaction/diffusion coupling, etc.) seems to defy analysis.

- The temptation, when faced with rather complex problems, is to look for empirical solutions, but these, potentially relevant in interpolation, are not adapted to the problem of predicting lifetime, which is an extrapolation problem.

- We now have powerful numerical methods accessible to non-specialists, to solve kinetic schemes, long ago considered to be irresolvable. These methods enable us to avoid simplifying hypotheses, necessary for analytical solutions, but sometimes difficult, or even impossible, to justify.

- Problems concerning non-Fickian diffusion, thermo-oxidation and hydrolysis have now and already gained satisfying solutions, even if the kinetic schemes can still be perfected. However, significant efforts still need to be made in the field of photooxidation and ageing of the interfacial zone in composites, glued joints, etc. Some problems, particularly mechanical stress/physical chemical ageing coupling, are still very far from being solved and must also researched in the future.

\subsection{Bibliography}

[AUd 07] Audouin L., Colin X., FAyolle B.,Verdu J., J. Testing Evaluation (ASTM), n 35 , p. 289, 2007.

[BOL 46] Bolland J.L., Proc. Roy. Soc (London), n 186, p. 218, 1946, Trans. Farad. Soc. $\mathrm{n}^{\circ}$ 42, p. 236 and p. 244, (1946), Quart. Rev., n 3, p. 1, 1949.

[DAK 48] DAKIN D.W., AIEC Trans 67, 113, 1948.

[Gau 99] Gautier L., Mortaigne B., Bellenger V., Verdu J., Polymer, n 41, p. 2481, 1999.

[Mer 02] Merdas I., Thominette F., Tcharkhtchi A., Verdu J., Compos. Sci. And Techn., $\mathrm{n}^{\circ} 62$, p. 487, 2002.

[STU 78] STRUIK L.C.E., Physical Ageing in amorphous polymers and other materials, Elsevier, Amsterdam, 1978. 


\subsection{More information}

Verdu J., « Vieillissement Physique, et Vieillissement Chimique », Techniques de l'Ingénieur, Traité des matériaux non métalliques AM 3-154, 2005.

Audouin L., Colin X., Fayolle B., Verdu J., «Un pas vers la modélisation cinétique du vieillissement », in G. Pijaudier-Cabot (dir.), Vieillissement et Durabilité des Matériaux, OFTA, Tec \& Doc, Paris, 2003.

VERDU J., « Vieillissement oxydant des Polymères », Initiation à la Chimie et la physico-chimie macromoléculaire, vol. 12, Chimie de l'élaboration des Matériaux Polymères, Chap. 9, p. 319-340 GFP, 2001.

HAMID S., Handbook of Polymer Degradation, Marcel Dekker, New York, 2000. 